\title{
THE PATTERNS AND
}

DETERMINANTS OF

PRICE SETTING IN

THE BELGIAN INDUSTRY

by David Cornille

and Maarten Dossche 
EUROPEAN CENTRAL BANK

\title{
WORKING PAPER SERIES
}

NO 6 I 8 / MAY 2006

EUROSYSTEM INFLATION

PERSISTENCE NETWORK

THE PATTERNS AND

DETERMINANTS OF

PRICE SETTING IN

THE BELGIAN INDUSTRY '

\author{
by David Cornille ${ }^{2}$ \\ and Maarten Dossche ${ }^{3}$
}

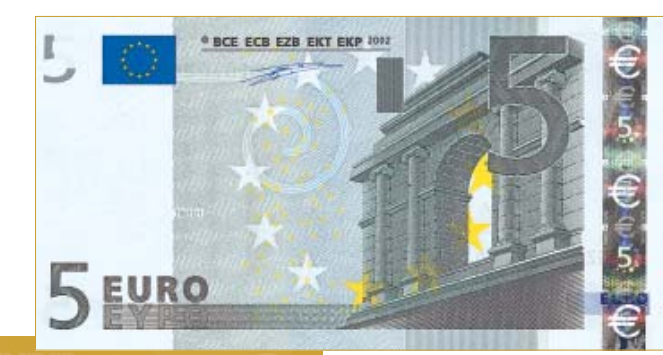

In 2006 all ECB

publications

will feature

motif taken

from the

$€ 5$ banknote.

This paper can be downloaded without charge from http://www.ecb.int or from the Social Science Research Network electronic library at http://ssrn.com/abstract_id $=899260$

I This study was developed within the scope of the Eurosystem Inflation Persistence Network (IPN). We are grateful to participants in this network and in particular Luc Aucremanne, Emmanuel Dhyne, Gerdie Everaert, Hugues Famerée, Philip Vermeulen and an anonymous referee for helpful comments and suggestions. In addition, we thank the Federal Public Service Economy, SMEs, Self-employed and Energy and in particular Koen Hooyberghs for providing us with the data.The views expressed in this paper are those of the authors and do not necessarily reflect the views of the National Bank of Belgium. All remaining errors are the authors'.

2 National Bank of Belgium, Boulevard de Berlaimont 14, 1000 Brussels, Belgium; e-mail:David.Cornille@nbb.be 3 National Bank of Belgium, Boulevard de Berlaimont 14, 1000 Brussels, Belgium; e-mail: Maarten.Dossche@nbb.be. SHERPPA, Ghent University, http://www.feb.ugent.be/soceco/sherppa/members/maarten/maartendossche.htm 


\section{The Eurosystem Inflation Persistence Network}

This paper reflects research conducted within the Inflation Persistence Network (IPN), a team of Eurosystem economists undertaking joint research on inflation persistence in the euro area and in its member countries. The research of the IPN combines theoretical and empirical analyses using three data sources: individual consumer and producer prices; surveys on firms' price-setting practices; aggregated sectoral, national and area-wide price indices. Patterns, causes and policy implications of inflation persistence are addressed.

Since June 2005 the IPN is chaired by Frank Smets; Stephen Cecchetti (Brandeis University), Jordi Galí (CREI, Universitat Pompeu Fabra) and Andrew Levin (Board of Governors of the Federal Reserve System) act as external consultants and Gonzalo Camba-Méndez as Secretary.

The refereeing process is co-ordinated by a team composed of Günter Coenen (Chairman), Stephen Cecchetti, Silvia Fabiani, Jordi Galí, Andrew Levin, and Gonzalo Camba-Méndez. The paper is released in order to make the results of IPN research generally available, in preliminary form, to encourage comments and suggestions prior to final publication. The views expressed in the paper are the author's own and do not necessarily reflect those of the Eurosystem.

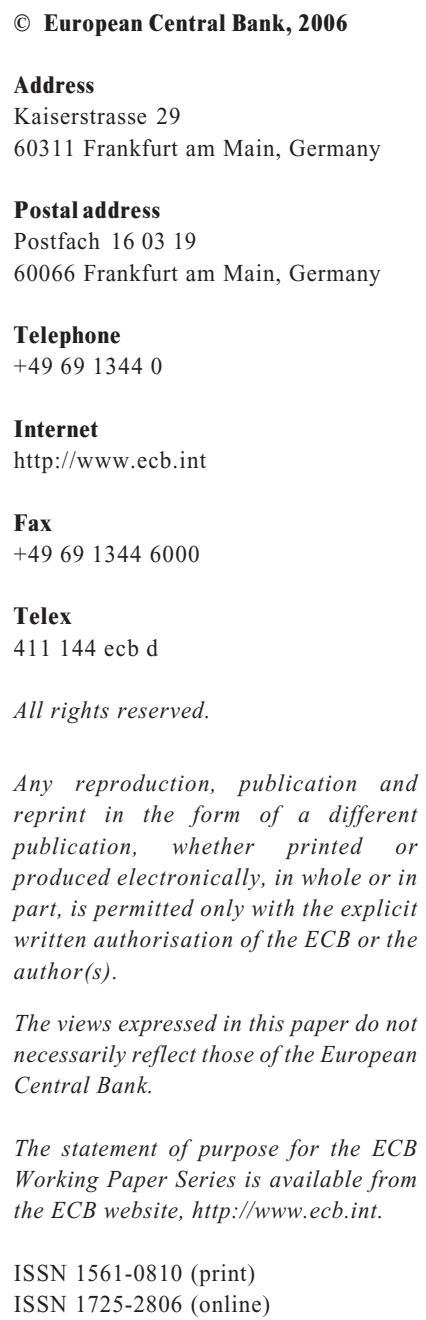

The views expressed in this paper do not necessarily reflect those of the European Central Bank. 


\section{CONTENTS}

Abstract 4

Non-technical summary 5

1 Introduction $\quad 7$

2 The data 8

3 Inflation and the distribution of price changes $\quad \|$

4 Main results regarding price stickiness for Belgian producer prices $\quad$ |2

4.1 The frequency of price adjustment ||2

4.2 The size of price adjustment I7

4.3 Inflation and its relationship with the frequency and size of price adjustment $\quad$ | 9

4.4 Downward nominal rigidity 22

4.5 Explaining the sectoral heterogeneity 23

5 Pricing-to-Market: differences between the behaviour on the domestic and foreign market 27

6 A comparison between consumer and producer price-setting

7 Summary and conclusions 32

References 34

Appendices 37

European Central Bank Working Paper Series 45 


\begin{abstract}
This paper documents the patterns and determinants of price setting in the Belgian industry. We analyse the micro data underlying the Producer Price Index (PPI) over the period from February 2001 to January 2005. On average only one out of four prices changes in a typical month, whereas the absolute size of a price change amounts to $6 \%$. The frequencies of price adjustment are particularly heterogeneous across sectors, which is determined by heterogeneity in the market and cost structure. We find no signs of downward nominal rigidity. A joint analysis of sizes and frequencies of price adjustment across time shows that price setting is characterised by both time- and state-dependent pricing. About $38 \%$ of the exported goods are affected by pricing-tomarket.
\end{abstract}

JEL classification: D40, E31

Keywords: producer price setting, nominal price rigidity, pricing-to-market, timedependent pricing, state-dependent pricing, staggering 


\section{Non-Technical Summary}

In this paper we gather the stylised facts of price setting in the Belgian industrial sector using the individual price records underlying the calculation of the Belgian Producer Price Index (PPI). This study is developed within the scope of the Eurosystem Inflation Persistence Network (IPN). During the period 2003-2005, this network of euro area central bank researchers conducted research on the patterns and determinants of inflation persistence and price setting in the euro area. In the context of the IPN numerous micro data sets, that are mostly managed by the national statistical institutes and are confidential, became available for research at the respective national central banks.

The ultimate goal of this research is to gain insights from micro data that are useful for microfounded macroeconomic models. In the first place, macroeconomic models should match macroeconomic stylised facts. However, using macroeconomic data only the calibration of macroeconomic models with different microfoundations may result in different predictions and/or policy prescriptions. Therefore, a particular model is more realistic if its microfoundations also match evidence from micro data. In this way, micro evidence can be very useful for designing realistic macroeconomic models. In this paper we empirically investigate the microfoundation of price adjustment, which is a key model ingredient in macroeconomic models for monetary policy analysis.

We have found a considerable degree of price stickiness in Belgian producer prices, as, on average, only one out of four prices changes in a typical month. The median implied duration amounts to 7 months. The average absolute size of a price change is $6 \%$ and is large compared with the prevailing rate of aggregate producer price inflation over the period covered. This suggests that large idiosyncratic shocks play an important role. Comparing the frequency and size of price adjustment for Belgian producer and consumer prices, we find that producer prices show more frequent but smaller price changes than consumer prices. This fact implies that price adjustment costs are smaller in the case of producer prices.

Across product categories, the frequency of price adjustment is very heterogenous as for some products (energy for instance) it amounts to $50 \%$, whereas for others (consumer non food and capital goods) it is close to $10 \%$. The size of the price changes is far less heterogenous across product categories. This difference in the degree of cross-sectional heterogeneity has two implications. First of all it implies that, in a cross-sectional perspective, the frequencies of price adjustment, rather than the sizes, are the margin along which price setting is made compatible with the sectoral characteristics. Therefore, the heterogeneity in the observed frequencies can be seen as a state-dependent outcome in response to the sectoror product specific economic conditions. Second, in the absence of a negative correlation 
between the frequencies and the sizes, this implies that differences in price adjustment costs do not play an important role in shaping the observed heterogeneity in the degree of price stickiness. In contrast, our econometric analysis shows that differences in firms' cost and market structure are important. In particular, a high share of energy inputs, a low share of labour inputs and a high degree of competition tend to increase the observed frequencies of price adjustment.

Price decreases are observed nearly as frequently as price increases, while they are both of the same size in absolute value. Moreover, the overall distribution of price changes which pools all product categories, turns out to be fairly symmetric. Overall, there is not much evidence of structural downward nominal rigidity. Across sectors, we found that if certain sectors at first sight seem to suffer from downward nominal rigidity, this is not a structural feature but endogenously generated by the level of sectoral inflation, as is predicted by economic theory.

The frequency of price adjustment displays a clear seasonal pattern. Whereas price adjustment is relatively uncommon in December, it is much more likely in January. This pattern can be compatible with time-dependent characteristics in price setting. However, once the separate role of upward and downward adjustment was taken into account, we also found a considerable degree of variability over time in the frequencies, whereas the average sizes do not change much over time. This in turn supports state-dependent pricing. This evidence obtained in the time dimension strengthens the one mentioned earlier in the crosssectional dimension. All in all, price setting of producer prices has both time-dependent and state-dependent characteristics. Similar conclusions were drawn on the basis of the analysis of consumer prices and in specific surveys on price setting, in the euro area in general and in Belgium in particular.

Finally, we find that $38 \%$ of products in the industrial sector is affected by pricing-tomarket. This is in line with the findings of a recent survey on price setting conducted by the National Bank of Belgium. 


\section{Introduction}

In this paper we gather the stylised facts of price setting in the Belgian industrial sector using the individual price records underlying the calculation of the Belgian Producer Price Index (PPI). This study is developed within the scope of the Eurosystem Inflation Persistence Network (IPN). During the period 2003-2005, this network of euro area central bank researchers conducted research on the patterns and determinants of inflation persistence and price setting in the euro area. Within the scope of the IPN, numerous micro data sets, that are mostly managed by the national statistical institutes and are confidential, became available for research at the respective national central banks. The IPN has used these data sets extensively in order to shed light on (i) the existence and characterisation of nominal rigidities in the euro area, (ii) the determinants of nominal rigidities and (iii) the empirical testing of alternative price setting models. The results of these national studies using micro data are summarised in Dhyne et al. (2006) for evidence from micro CPI data, in Vermeulen et al. (2006) for evidence on producer prices based on either micro PPI or qualitative data from business cycle surveys and in Fabiani et al. (2005) for evidence from specific surveys on price setting. The implications these new results have for macroeconomic modelling are summarised in Altissimo et al. (2006), Álvarez et al. (2006) and Angeloni et al. (2006).

The ultimate goal of this research is to gain insights from micro data that are useful for microfounded macroeconomic models. In the first place, macroeconomic models should match macroeconomic stylised facts. However, the calibration of macroeconomic models with different microfoundations using macroeconomic data only may result in different predictions and/or policy prescriptions. Therefore, a particular model is more realistic if its microfoundations also match evidence from micro data. In this way, micro evidence can be very useful for designing realistic macroeconomic models. In this paper we empirically investigate the microfoundation of price adjustment, which is a key model ingredient in macroeconomic models for monetary policy analysis.

The earliest studies on price setting using micro prices go back to Cecchetti (1986) for magazine prices, Kashyap (1992) for catalogue prices and Lach and Tsiddon (1992) for food. Research using large data sets containing micro data that cover almost all consumer and producer products has been undertaken only recently in e.g. Bils and Klenow (2004) for the U.S. and the IPN for the euro area. Because of the finding that pricing practices differ significantly across goods, the conclusions of the earlier studies based on rather homogeneous goods are not necessarily representative for the entire economy.

Although the basic findings of this paper confirm previous results obtained using large micro data sets, it also contains a number of new results. First, it adds to the scarce number 
of studies using micro producer prices compared to the number of studies using consumer prices. We are only aware of the studies of Carlton (1986) for the United States, Álvarez et al. (2005) for Spain, Sabbatini et al. (2006) for Italy, Dias et al. (2004) for Portugal and Stahl (2006) for Germany that use quantitative micro producer prices. Second, because the Belgian National Statistical Institute (NSI) computes a PPI index both for the Belgian and the foreign market, two separate price trajectories are observed for each product that is sold both in Belgium and abroad. This allows us to measure the extent of pricing-to-market, which is unprecedented using a large micro data set.

In Section 2 we describe the data set. Section 3 provides a quick reminder of the relation between aggregate inflation, the distribution of price changes and the statistics summarising the shape of this distribution. In Section 4 we analyse the frequency and the size of producer price changes at the aggregate level, the level of the sectoral cross-section and over time. Section 5 addresses pricing-to-market. Section 6 compares the frequency and the size of price adjustment for consumer and producer products on the basis of a matched sample. The conclusions are drawn in Section 7.

\section{The Data}

Our data set consists of price records collected by the Belgian NSI in order to compute the Belgian PPI. The PPI is a short-term indicator measuring price developments of industrial products on a monthly basis. The common European rules concerning the collection of price records have been established in a number of European Council and Commission Regulations. The rules are described in a methodological manual from Eurostat (2002). Prices are recorded ex-factory, including all duties and taxes except VAT. They refer to actual transaction prices, not list prices. Finally, they refer to the price at the time the order is placed, not at the time the commodities leave the factory. The Belgian prices are collected through a monthly telephone survey from the firms that take part on a voluntary basis.

The NSI allowed access to its data base for research under strict confidentiality. The micro data we have access to refer to $83 \%$ of the PPI, with base year 2000, which was introduced in March 2002. ${ }^{1}$ The prices are quoted in euro, and for each price quote we observe a product code $^{2}$, a firm code, a code identifying whether the price is valid in Belgium or abroad, a code describing the product version ${ }^{3}$, and the month and year the price was

\footnotetext{
${ }^{1}$ The prices of goods that were not available (17\% of the PPI) in our data set mainly correspond to goods sold abroad.

${ }^{2}$ We observe the PRODCOM code. PRODCOM stands for PRODucts of the European COMmunity.

${ }^{3}$ When the price of a product can no longer be observed, the product is replaced by a close substitute from the same firm. This replacement implies the end of the price trajectory for the old product, whereas it implies the start of the price trajectory for the new product. Product replacement therefore does not imply
} 
recorded. The sample contains monthly price level data from January 2001 to January 2005 of around 1,500 firms. The monthly price changes are available for the four-year period as from February 2001 to January 2005, so that the sample we actually use is seasonally balanced. Firms may not report a price during a certain month, or even stop participating in the survey so that the coverage of the data set slightly varies from one month to another. The average number of price quotes per month is $2,100 .{ }^{4}$ The data set contains about 100,000 price quotes, of which 80,000 quotes cover the goods sold in the domestic market, and 20,000 cover the goods sold in the external market. Between February 2002 and January 2005 , the official twelve-month inflation rate varied between $-1.5 \%$ and $6 \%$, while the average twelve-month inflation rate was $1.5 \%$. The twelve-month inflation rate in our data set varied between $-3.3 \%$ and $4.9 \%$, while the average twelve-month inflation rate amounted to $0.7 \%$. We find a correlation coefficient of 0.72 between the official inflation rate and the inflation rate in the data set. All in all, our sample period is characterised by considerable short-run inflation variability, while trend inflation was relatively low.

The main $\mathrm{NACE}^{5}$ branches covered by the data set are Mining, Quarrying, Manufacturing Industry, Electricity, Gas and Water Supply. Together these branches constitute the national accounts category Total Industry Excluding Construction, or simply the Industry. The service sector is not covered. The NACE classification of our data set can be disaggregated into 27 so-called NACE 2-digit level branches, 97 NACE 3-digit level branches, and 207 NACE 4-digit level branches. On the basis of the NACE classification an alternative breakdown in the so-called Main Industrial Groupings (MIGs) can be obtained. In our analysis we will switch between different levels of aggregation depending on the data requirements of the respective calculations. As long as there were enough observations, we calculated the statistics at the most disaggregate level. The regression analysis was conducted at the NACE 3-digit level in order to guarantee the availability of explanatory variables for as many branches as possible.

In Figure 1 we have graphed out a number of typical price trajectories of goods in the data set. On the basis of these plots a number of observations can be made. First, the price for some products changes only infrequently, whereas for other products it changes every month. Second, for some products, and notwithstanding the positive trend inflation, the nominal price decreases over the sample period. Third, as has already been mentioned, our data set allows the comparison between the price of the same product depending on

${ }^{4}$ During the first months of 2001 the dataset only covers about 1,800 price quotes per month. If we would discard the first months of 2001 , the condition to have a seasonally balanced sample would imply that all observations of 2001 need to be discarded, which is about $25 \%$ of the dataset. We chose not to do this.

${ }^{5} \mathrm{NACE}$ is the Eurostat classification scheme of economic activities. It stands for 'Nomenclature générale des Activités économiques dans les Communautés Européennes' or the General Industrial Classification of Economic Activities within the European Communities.
} 
whether the good is sold on the Belgian market or on the foreign market. In the case of the selected price trajectory for processed cheese the price is persistently lower in case the product is sold abroad compared to when the product is sold in Belgium. Finally, for the product classified under Other poultry meat, the price remains fairly stable for a long period and then changes dramatically. The demand for the product or its costs must have been hit by a sizeable idiosyncratic shock.
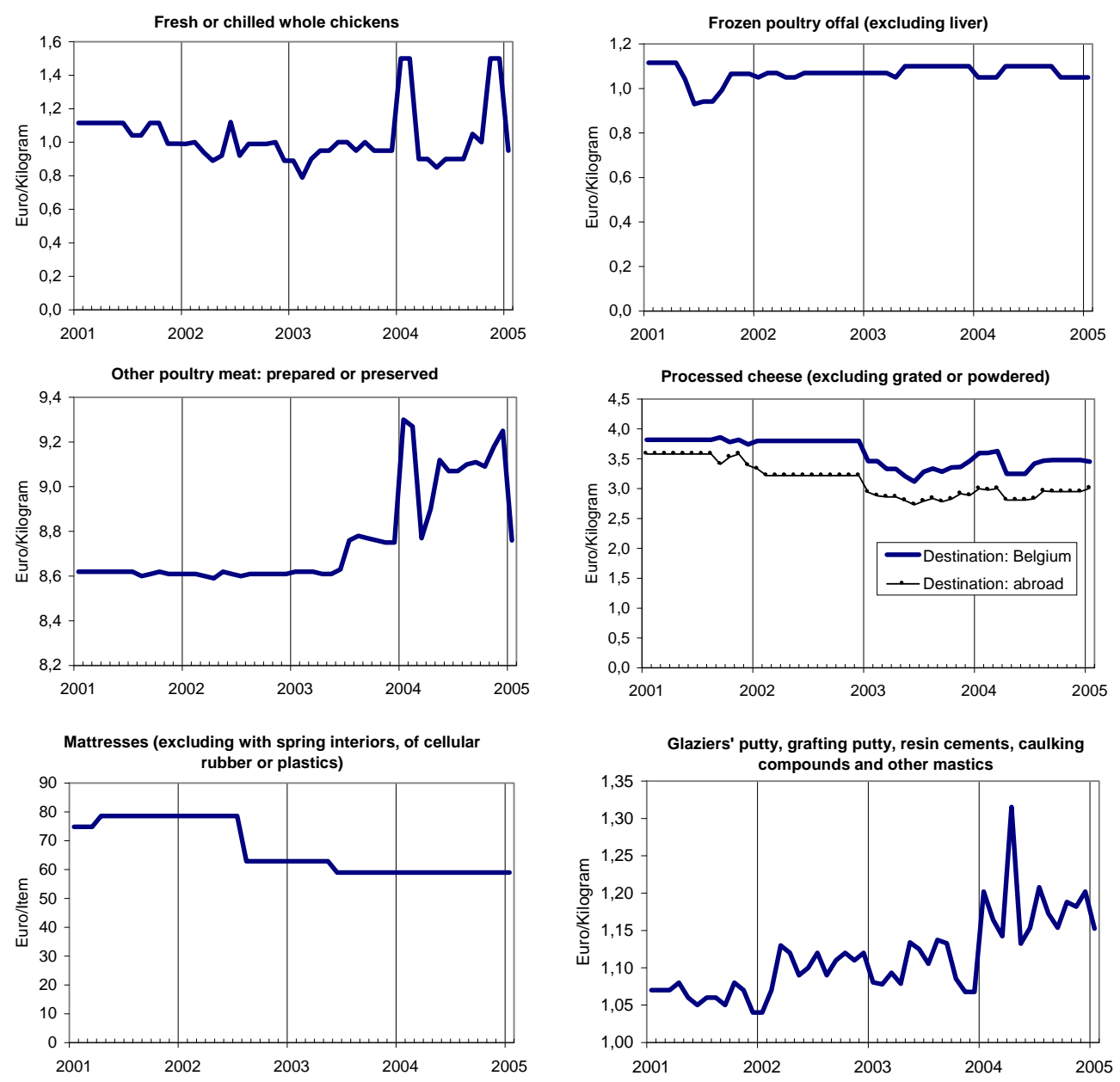

Figure 1: Examples of Typical Price Trajectories

\section{Inflation and the Distribution of Price Changes}

Because our data set only covers 4 years, we will not assess price rigidity through the direct measurement of the duration of price spells, as has been done in e.g. Aucremanne and Dhyne (2004) or Baudry et al. (2004). The analysis of price rigidity is solely based on 
the frequency of price adjustment. Methodological details on the computation of these frequencies are shown in Appendix A. This approach has two advantages compared to the duration approach. First, it uses all data regardless of whether a price spell has been censored or not, and, second, there is no selection bias towards shorter price spells. We consider a price usable if there is at least one price quote in the preceding or following month. This is a minimum requirement for calculating a frequency.

As the statistics we use are linked to the distribution of price changes, we give here a quick overview of how these statistics summarise the properties of this distribution. These statistics should tell us whether prices are sticky, whether they are characterised by downward nominal rigidity, or even whether price setting is time- or state-dependent.

\section{Symmetric distribution, perfect price flexibility}

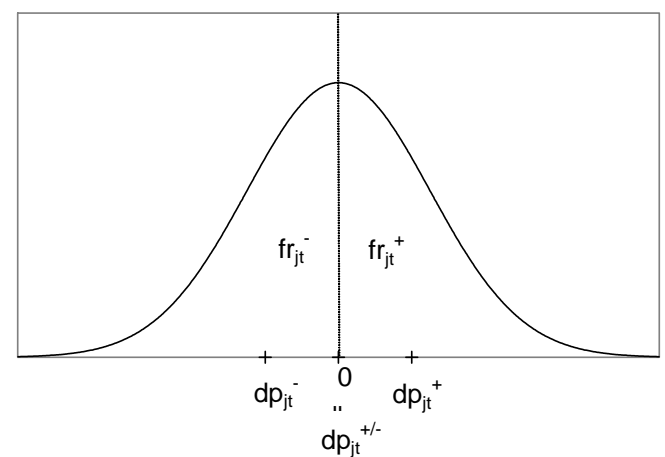

Symmetric distribution, price stickiness

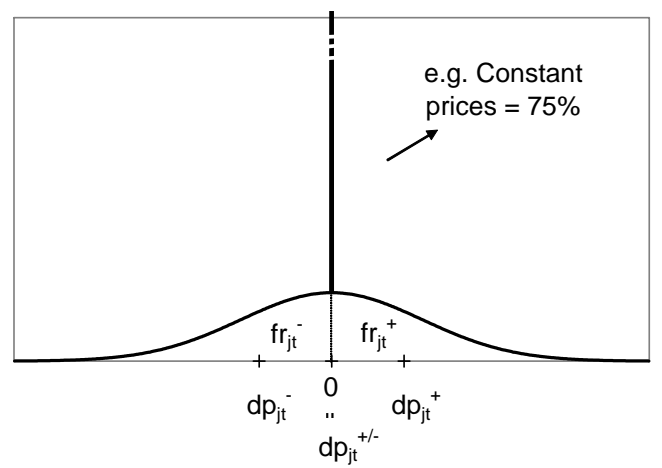

Figure 2: Hypothetical Price Distributions

Figure 2 shows that in the case of aggregate price stability and perfect price flexibility, individual prices will constantly change due to relative price or idiosyncratic shocks. Assuming that the distribution of idiosyncratic shocks is normal, the distribution of price changes will also be normal with a mean equal to zero. In that case, the probability of observing a zero price change is equal to zero. However, in the case of nominal price stickiness, a number of prices will neither increase nor decrease. This phenomenon creates a distribution of price changes with a large spike at zero.

The inflation rate at the most disaggregate level can be decomposed as follows:

$$
\begin{aligned}
\pi_{j t} & =\left[f r_{j t}^{+/-}\right] \cdot\left[d p_{j t}^{+/-}\right] \\
\pi_{j t} & =\left[f r_{j t}^{+}+f r_{j t}^{-}\right] \cdot\left[\frac{f r_{j t}^{+}}{f r_{j t}^{+}+f r_{j t}^{-}} \cdot d p_{j t}^{+}+\frac{f r_{j t}^{-}}{f r_{j t}^{+}+f r_{j t}^{-}} \cdot d p_{j t}^{-}\right] \\
\pi_{j t} & =f r_{j t}^{+} \cdot d p_{j t}^{+}+f r_{j t}^{-} \cdot d p_{j t}^{-}
\end{aligned}
$$

where $\pi_{j t}$ is the inflation rate of NACE 4-digit product category $j$ at time $t .{ }^{6}$ The inflation

\footnotetext{
${ }^{6}$ The NSI uses firm- and product-specific turnover to weight each price observation. As we had no access
} 
rate in period $t$ can be written as the product of the average price change $d p_{j t}^{+/-}$across firms in product category $j$ in period $t$ and the frequency of observing a price change $f r_{j t}^{+/-}$ in product category $j$ at time $t$. The overall frequency of price adjustment, in turn, can be decomposed into the sum of the frequency of an upward price change $f r_{j t}^{+}$and the frequency of a downward price change $f r_{j t}^{-}$. The overall average price change, then, is equivalent to the sum of the product of the frequency of an upward price change $f r_{j t}^{+}$and the average upward price change $d p_{j t}^{+}$, and the product of the frequency of a downward price change $f r_{j t}^{-}$and the average downward price change $d p_{j t}^{-}$. In Figure 2 , the frequency of an upward and a downward price change correspond to the area below the bell-shaped curve right and left from zero, respectively. The average upward and downward price changes correspond to the average of the respective upward and downward price change distributions. Below, we will sometimes present the absolute value of a downward price change.

These basic statistics obtained at the NACE 4-digit level have subsequently been aggregated at different levels of breakdown. When aggregating, the PPI weights of the corresponding product group were used. It should be noted that the NACE 4-digit products in the entire market are the result of the aggregation of the NACE 4-digit products in the domestic and the foreign market using the PPI weights. The statistics we have just presented are provided for the entire market at the NACE 3-digit level in Appendix C.

\section{Main Results Regarding Price Stickiness for Belgian Producer Prices}

\subsection{The Frequency of Price Adjustment}

Table 1: Weighted Monthly Frequencies of Price Adjustment (percentages)

\begin{tabular}{llll}
\hline \hline Entire market & Change $\left(f r^{+/-}\right)$ & Up. change $\left(f r^{+}\right)$ & Down. change $\left(f r^{-}\right)$ \\
\hline Consumer food & 20 & 11 & 9 \\
Consumer non-durables & 11 & 6 & 5 \\
Consumer durables & 14 & 8 & 6 \\
Intermediate goods & 28 & 15 & 14 \\
Energy & 50 & 33 & 17 \\
Capital goods & 13 & 7 & 6 \\
\hline Total & $\mathbf{2 4}$ & $\mathbf{1 3}$ & $\mathbf{1 1}$ \\
\hline
\end{tabular}

\section{Average Frequency and Implied Duration of Price Spells}

On average, $24 \%$ of prices are adjusted every month. This measure is a weighted average of the frequencies originally computed for each of the products at the NACE 4-digit level (see

to these weights, we assumed that every observation has an equal weight at the NACE 4-digit level. We then used the official PPI weights to aggregate to higher levels of aggregation. 
Appendix A for details). As each month only one out of four prices changes, this implies that there is a considerable degree of price stickiness.

Starting from the frequencies of price adjustment, implied durations can be obtained by inverting the frequencies. While this inversion is straightforward at the most disaggregate level, it is less so at the aggregate level. Inverting the average frequency yields an average implied price duration of 4.2 months, whereas we obtain an implied duration of 10 months when calculating the weighted average of the implied durations obtained at the NACE 4digit level (i.e. the inverse of the frequencies at this level of breakdown). The observation that the latter is higher is also valid for other countries and follows from Jensen's inequality ${ }^{7}$. Because of this discrepancy, Bils and Klenow (2004) chose to calculate the weighted median of the inverse frequencies. This statistic amounts to 7 months for our data. The inverse of the weighted median frequency gives the same result. It should be noted that Aucremanne and Druant (2005), using survey evidence, found that the average price duration in the industry amounts to 9.6 months, which is comparable to the average of the implied durations at the disaggregate level in our data set (10 months). In the remainder of the paper we will continue to work with the average frequency of a price change $\mathrm{fr}^{+/-}$.

Compared to other micro studies of quantitative PPI prices, our average frequency of price adjustment $\mathrm{fr}^{+/-}$is not particularly high or low. The aforementioned studies analysing producer prices find that the frequency of adjustment amounts to $22 \%$ in Germany, $15 \%$ in Italy, $21 \%$ in Spain and $23 \%$ in Portugal. In sum, except for Italy, all studies find a frequency of slightly more than $20 \%$. For producer prices there is no recent evidence available for the US. Bils and Klenow (2004) find an average frequency of price adjustment of $25 \%$ for consumer prices in the US, while Dhyne et al. (2006) find an average frequency of $15 \%$ for euro area consumer prices.

\section{Sectoral Heterogeneity}

There is considerable sectoral heterogeneity in the frequency of price adjustment. Comparing the price adjustment frequencies in Table 1 across the six Main Industrial Groupings (MIGs), that classify goods according to their purpose of use, we find that the frequency of price adjustment ranges from $50 \%$ for energy to $11 \%$ for consumer non-durables. Especially prices for food, intermediate goods and energy often change, whereas consumer non-durables, consumer durables and capital goods change less often. This indicates that there are more frequent price changes for unprocessed products that have not undergone a number of transformations.

\footnotetext{
${ }^{7}$ For more details concerning this issue we refer to Baudry et al. (2004).
} 


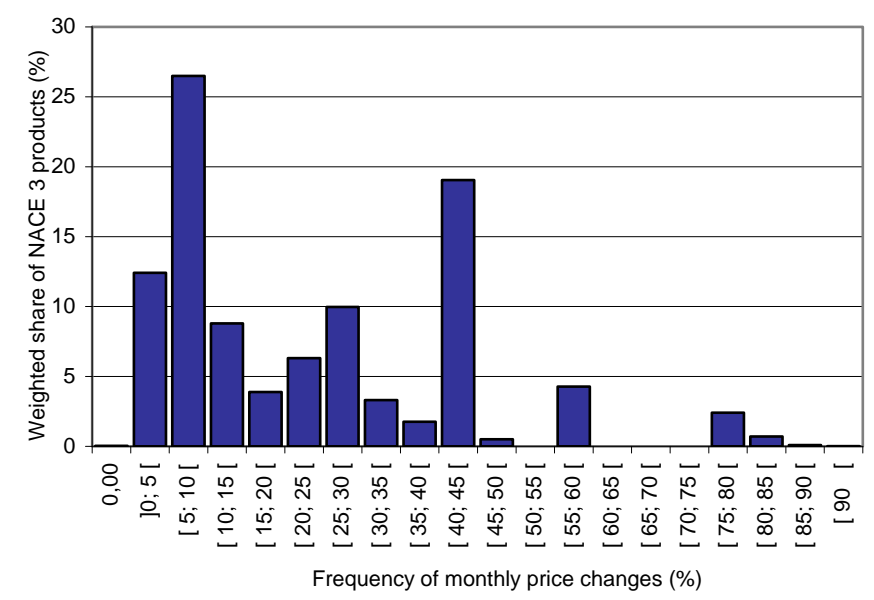

Figure 3: Distribution of Price Change Frequencies

It follows from Figure 3, showing the distribution of price change frequencies across product categories, that the degree of heterogeneity is substantially more pronounced at the NACE 3-digit product category level than at the level of the six MIGs (see Table 1). Whereas the frequency of price adjustment exceeds $50 \%$ for some product categories (representing approximately $10 \%$ of the PPI share we analyse), it is below $10 \%$ for other products (representing nearly $40 \%$ of the PPI share we analyse). The total variance of the frequencies across the NACE 3-digit product categories can be broken down in the variance between the six MIGs and the variance within these MIGs: 25\% of the overall variance stems from the variance between MIGs and the remaining $75 \%$ is due to the variance within MIGs. This shows that the MIG classification only captures a relatively minor fraction of the total heterogeneity in the frequencies of price adjustment and suggests that the NACE 3-digit breakdown is the relevant one for a deeper examination of this type of heterogeneity (see Section 4.5). Further investigation of the factors explaining the observed heterogeneity is needed, as at this stage of the analysis it can not be inferred whether the differences in price adjustment frequencies reflect (i) differences in price adjustment costs, (ii) differences in the competitive structure of the market in which the respective goods are sold or (iii) differences in the size and the volatility of the shocks hitting these goods (e.g. through the inputs needed in their production process).

The heterogeneity in the price adjustment frequency is not only important for macro modelling per se, but also for the optimal monetary policy implications as has been shown by Aoki (2001) and Benigno (2004). Both papers find that monetary policy should attach more weight to the stabilisation of inflation in the more sticky sectors/countries. The heterogeneity in these papers originates from exogenously assumed differences in the degree of 
nominal price stickiness. But it may also be the case that the heterogeneity observed in our data set results from heterogeneity in the underlying cost and/or market structures, which endogenously creates a heterogeneous price-setting pattern, than from exogenous differences in price adjustment costs. In that case, it is still to be examined whether the implications of Aoki (2000) and Benigno (2004) for optimal monetary policy remain valid.

\section{Time Variation in the Frequency of Price Adjustment}

There is considerable variation over time in the monthly frequency of price adjustment. Especially in December the frequency of price adjustment drops dramatically. In January this is largely compensated, as, unlike in any other month of the year, more than $40 \%$ of the prices are adjusted. This marked seasonality in the frequency of price adjustment suggests that firms follow time-dependent pricing policies. However, this might also be the result of a time-dependent pattern in the underlying production cost development or in the development of price adjustment costs. See Levy et al. (2005) on the latter explanation. In both cases, the observed seasonal pattern would then still be compatible with an intrinsically state-dependent behaviour.

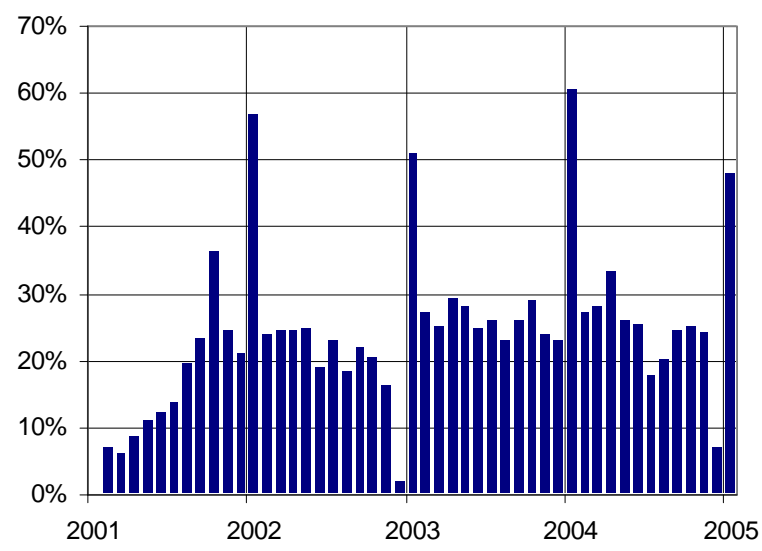

Figure 4: Frequency of Price Change across Time

Except for December and January, the frequency of price adjustment remains rather stable. At the beginning of 2001 the frequency of price adjustment is however below average. We ascribe this to the somewhat lower product coverage of the sample (see Section 2).

The fairly stable temporal behaviour of the aggregate frequency of price adjustment suggests that price setting is staggered rather than synchronised, at least at the aggregate level. In two papers Taylor $(1979,1980)$ introduced the notion of staggered price setting. He showed that in the case of small nominal rigidities, where half of the firms can adjust 
wages in odd periods and the other half of firms can adjust wages in even periods, nominal shocks could result in considerable persistence. The presence of staggering is one of the factors which allows a small (and therefore plausible) degree of nominal rigidity to generate persistent effects in macroeconomic models ${ }^{8}$. Finding this fairly staggered pattern at the aggregate level would be compatible with time-dependent pricing behaviour. In the two most popular time-dependent pricing rules used in macroeconomic models (Taylor contracts and Calvo pricing) the frequency of price adjustment is indeed stable over time.

Fisher and Konieczny (2000) developed a test ${ }^{9}$ for micro data in order to find out to what extent price adjustment is bunched in certain periods or not. Perfect synchronisation of price changes occurs when either all firms change their price simultaneously or no firms change prices. On the basis of this assumption, Fisher and Konieczny (2000) propose a statistical measure of price synchronisation. This measure is the ratio between the observed standard deviation of the monthly frequencies of price changes at the product category level and the theoretical standard deviation, implied by the average frequency of price changes computed at the product category level, that would be observed under perfect synchronisation. The ratio is equal to 1 in the case of perfect synchronisation. Conversely, it is 0 in the case of complete absence of synchronisation (or perfect staggering), as for Taylor-contracts or Calvo price setting.

We have calculated the Fisher-Konieczny ratio for both the 4-digit and the 2-digit NACE breakdown. At the NACE 4-digit level, we find a substantial degree of heterogeneity in the results. Price adjustment in some sectors is much more synchronised compared to other sectors. For approximately $15 \%$ of the PPI share we analyse, the synchronisation measure exceeds 0.8. For the bulk of the product categories (representing nearly $80 \%$ of the PPI share we analyse) the synchronisation measure lies between 0.25 and 0.75 . For only a very few number of product categories synchronisation is very low. Synchronisation is possibly linked to market concentration, when higher market concentration eases synchronisation of price changes, or to simultaneous shocks in the prices of inputs.

\footnotetext{
${ }^{8}$ Chari, Kehoe and McGrattan (2000), stress that staggering in itself does not generate a significant degree of persistence, but other authors - e.g. Jeanne (1998) and Eichenbaum and Fisher (2004) - show that the combination of staggered price setting and the existence of real rigidities is important in this respect. ${ }^{9}$ The synchronisation ratio proposed by Fisher and Konieczny $(2000)$ is calculated as follows: $F K_{j}=$ $\sqrt{\frac{1}{\tau-1} \frac{\sum_{t=2}^{\tau}\left(f r_{j t}^{+/-}-f r_{j}^{+/-}\right)^{2}}{f r_{j}^{+/-}\left(1-f r_{j}^{+/-}\right)}}$. In the case of perfect synchronisation the ratio equals 1, while in case of perfect staggering it takes the value 0 .
} 

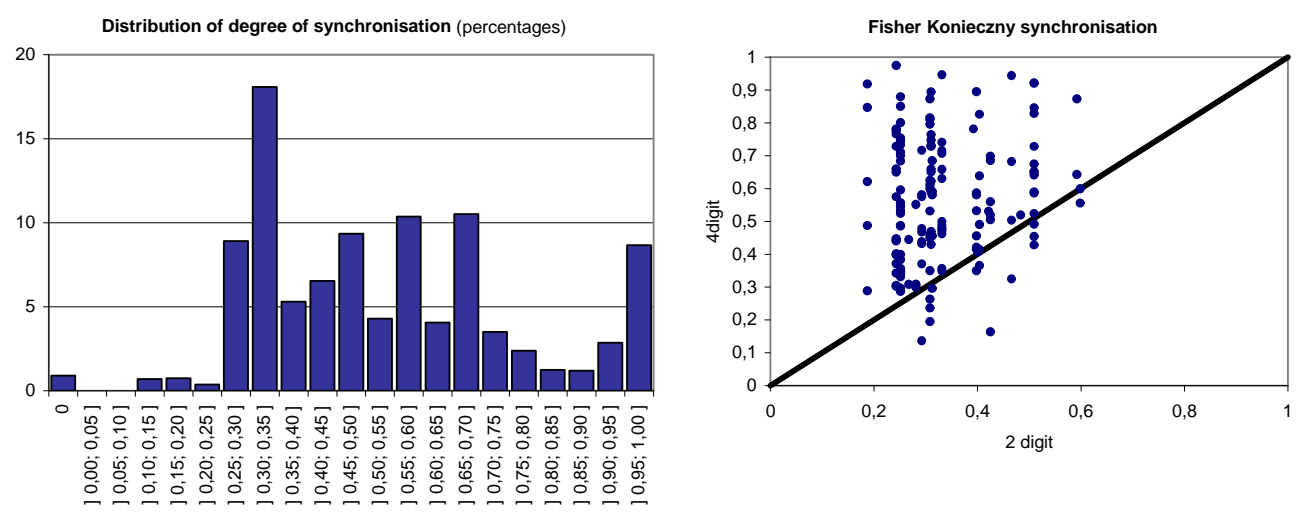

Figure 5: Synchronisation of Price Changes

When we compare the synchronisation in the NACE 4-digit product categories with the synchronisation in the corresponding NACE 2-digit categories, we find that the average synchronisation ratio at the more detailed level almost always exceeds the synchronisation ratio calculated for the entire NACE 2-digit product category. This implies that price adjustment is much more synchronised in the NACE 4-digit sectors than in the NACE 2digit sectors. Apparently, synchronisation is more pronounced when the goods produced in a particular sector are more homogeneous compared to a higher aggregate. This finding is in line with Dhyne and Konieczny (2006) who conduct a rigorous analysis of this phenomenon for Belgian consumer prices. It is also in line with our finding, that, apart from its seasonal pattern, there is not much time variation in the observed aggregate frequency of price change. The evidence supports a model of endogenous staggering like that of Bhaskar (2002) with synchronisation of price adjustment within sectors, whereas across sectors price adjustment is staggered. We interpret this finding as favourable for a model of state-dependent pricing with idiosyncratic shocks that are correlated within sectors, but uncorrelated across sectors.

\subsection{The Size of Price Adjustment}

Table 2: Weighted Size of Monthly Price Changes (percentages)

\begin{tabular}{llll}
\hline \hline Entire market & Abs. Change $\left(\left|d p^{+\mid-}\right|\right)$ & Up. change $\left(d p^{+}\right)$ & Down. change $\left(\left|d p^{-}\right|\right)$ \\
\hline Consumer food & 5 & 5 & 5 \\
Consumer non-durables & 4 & 4 & 5 \\
Consumer durables & 3 & 3 & 3 \\
Intermediate goods & 7 & 7 & 6 \\
Energy & 3 & 3 & 4 \\
Capital goods & 6 & 5 & 7 \\
\hline Total & $\mathbf{6}$ & $\mathbf{6}$ & $\mathbf{6}$ \\
\hline
\end{tabular}




\section{Average Size}

The average size of a price change (in absolute value) amounts to $6 \%$. This is sizeable compared to the prevailing inflation rate (1.5\% on an annual basis for the overall PPI, and $0.7 \%$ on an annual basis for the data set used in this paper). Particularly, as the degree of price stickiness described above is not extremely high, the size of the price changes is well in excess of what is needed to catch up with aggregate inflation. In line with Golosov and Lucas (2005) we interpret this as evidence in favour of an important role for large idiosyncratic shocks. The coexistence of both upward and downward price adjustment further corroborates this interpretation.

Although somewhat lower than for Belgium, large average sizes of price adjustment compared to the prevailing inflation rate are also found in other European studies regarding producer prices (Stahl (2006) for Germany: 3.3\%, Sabbatini et al. (2006) for Italy: 4.2\%, Álvarez et al. (2005) for Spain: 4.8\% and Dias et al. (2004) for Portugal: 3.8\%). It should be pointed out, though, that the average size of price adjustment for producer prices is smaller than in the case of consumer prices. Sizes close to or even exceeding $10 \%$ were found for consumer prices in Belgium (Aucremanne and Dhyne, 2004), in the euro area as a whole (Dhyne et al., 2006) and in the US (Bils and Klenow, 2004).

\section{Sectoral Heterogeneity}

Contrary to the frequency of price changes, we find a relatively low degree of heterogeneity in the sizes of the price changes across the six MIGs. Table 2 shows that the average price change ranges between $3 \%$ for consumer durables and $7 \%$ for intermediate goods. At the level of the NACE 3-digit product categories, heterogeneity is again substantially more pronounced. We find that the variance between the six MIGs represents only $20 \%$ of the overall variance, the bulk of it stemming from the variance within MIGs. This notwithstanding, also at this detailed level of breakdown we find that there is far less heterogeneity in the sizes than in the frequencies of price adjustment. While the overall cross-sectional standard deviation of the frequencies amounts to $20 \%$, it is only $3 \%$ for the absolute value of the sizes. This implies that, in a cross-sectional perspective, the frequencies of price adjustment, rather than the sizes, are the margin along which price setting is made compatible with the sectoral characteristics. We interpret the heterogeneity in the observed frequencies as a state-dependent outcome in response to the sector- or product-specific economic conditions. This interpretation is compatible with the previous interpretation that synchronisation within sectors and staggering across sectors supports a model of state-dependent pricing with idiosyncratic shocks that are correlated within sectors, but uncorrelated across sectors. 
Time Variation in the Sizes of Price Adjustment

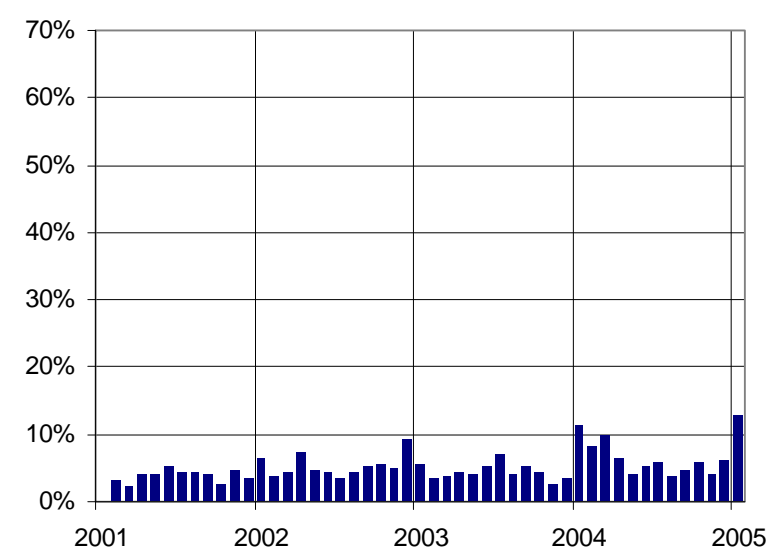

Figure 6: Absolute Size of Price Change across Time

Contrary to the frequency of price changes, there is much less variation over time in the monthly observed average sizes, in absolute value. We find almost no seasonal variation in the size of the changes. ${ }^{10}$ Once abstraction is made from this difference in the seasonal behaviour of the frequencies and the sizes, the monthly evolution of the average price changes in absolute value is not particularly more variable than the one observed for the frequencies. The latter finding then raises the question what drives the observed movements in the monthly aggregate inflation rate. This issue is analysed in the next section.

\subsection{Inflation and its Relationship with the Frequency and Size of Price Adjustment}

The fairly staggered picture for the frequencies of price adjustment at the aggregate level disappears when price increases and price decreases are analysed separately. Both the frequency of upward adjustment and the frequency of downward adjustment vary considerably over time. Apart from the months December and January, in which the seasonal pattern tends to affect both frequencies in the same direction, a negative correlation between the frequencies of upward and downward price changes is observed. Excluding all observations relating to the months December and January, the correlation between upward and downward price change frequencies is -0.53 for the period 2002 to $2004 .{ }^{11}$ This negative correlation implies that the difference between upward and downward price adjustment frequencies varies considerably over time. As is shown in Figure 7, this difference, in turn, is

\footnotetext{
${ }^{10}$ We regressed the absolute value of price changes on a constant and 11 monthly dummy variables, and found only a significant seasonal effect in January.

${ }^{11}$ See footnote 4 for the reason why we here excluded the data for 2001.
} 
highly correlated over time with the monthly aggregate inflation rate in the data base. The correlation between both phenomena is 0.81 . Changes over time in the proportion of price increases relative to price decreases seem to be an important driving force behind observed aggregate inflation.
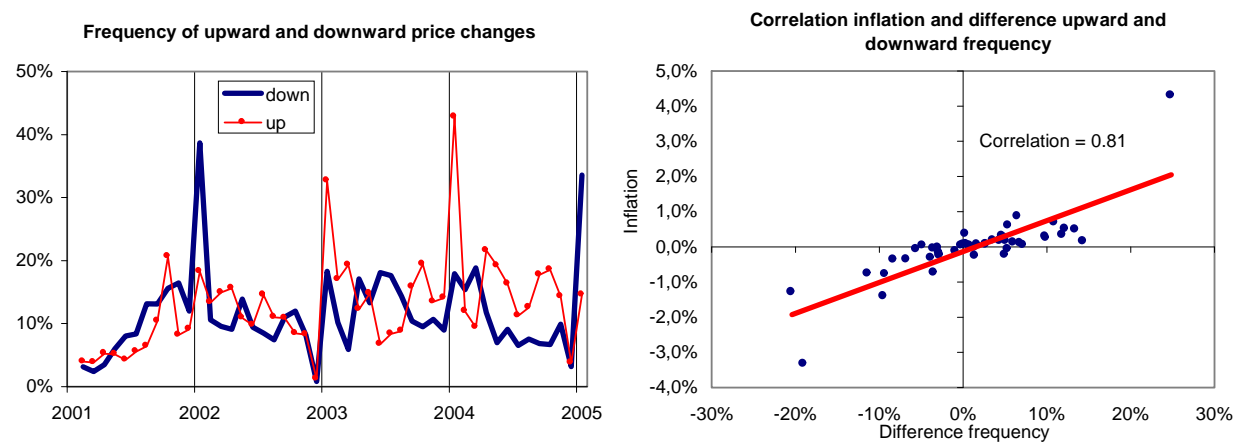

Figure 7: Inflation and the Frequency of Price Adjustment
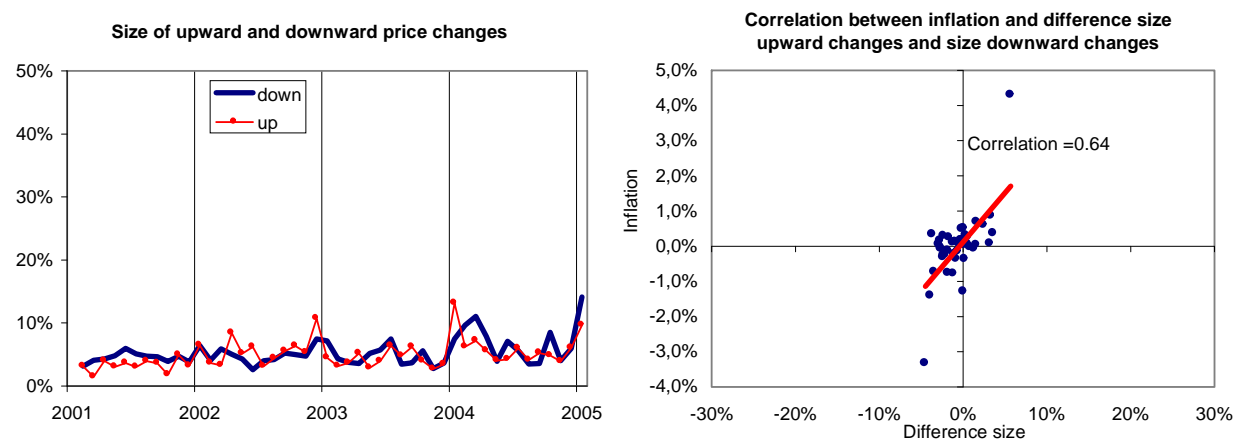

Figure 8: Inflation and the Size of Price Adjustment

As for the size of the price changes, a similar analysis yields different results in several respects. First of all, the image of absence of pronounced variation over time is not fundamentally altered when the sizes of upward and downward price adjustments are considered separately. Moreover, for the sizes, there is evidence of a positive correlation between the upward and the downward changes. This correlation amounts to 0.55 . This positive correlation dampens the variability of the difference between the size of the upward price changes and the absolute value of the size of the downward price changes. As is shown in Figure 8 , the correlation of this difference with inflation is smaller than for the difference in frequency, as it amounts to 0.64 (and only 0.47 when the two outliers in the graph are excluded), compared to 0.81 for the difference of the frequencies. 
In Appendix D we decompose the variance of aggregate inflation and find that according to this decomposition the difference in frequencies of price adjustment accounts for $24 \%$ of aggregate inflation variance, whereas the difference in the size of price changes only accounts for $8 \%$ of aggregate inflation variance. The rest of the variance of aggregate inflation results from other terms and a number of covariances.

In order to fully assess the driving forces behind the variability of inflation, in Appendix D we build on Klenow and Kryvtsov's (2006) classification of the different contributors to inflation in either a state-dependent component (SDP) or a time-dependent component (TDP). The intuition behind their classification is that the TDP terms capture changes in the intensive margin, which account for all of the variation in inflation in staggered TDP models, whereas the SDP terms involve changes in the extensive margin, which only contribute in SDP models. The sole difference between their decomposition and ours is that we explicitly take into account upward and downward price changes.

Table 3: Inflation Variance Decomposition ${ }^{12}$

\begin{tabular}{l|c|c|c|c}
\hline \hline & \multicolumn{2}{|c|}{ Incl. Jan. \& Dec. } & \multicolumn{2}{c}{ Excl. Jan. \& Dec. } \\
\hline & TDP & SDP & TDP & SDP \\
\hline Klenow \& Kryvtsov & $36 \%$ & $64 \%$ & $86 \%$ & $14 \%$ \\
Alternative Decomposition & $8 \%$ & $92 \%$ & $16 \%$ & $84 \%$ \\
\hline
\end{tabular}

When we calculate Klenow and Kryvtsov's (2006) decomposition of the variance of inflation we find that $36 \%$ of the variance is accounted for by time-dependent pricing, whereas $64 \%$ is accounted for by state-dependent pricing. If we apply our alternative decomposition, that accounts for the difference between upward and downward price changes, we, however, find that only $8 \%$ of the total variance comes from time-dependent pricing. It might be argued that the state-dependent pricing component in this decomposition is spuriously high due to the high seasonality in the frequency of price adjustment. The latter is rather a symptom of time-dependent pricing, but is a source of variance in the frequencies which is considered as a state-dependent pricing factor in the Klenow and Kryvtsov (2006) decomposition. Therefore, we have also calculated both decompositions excluding the data for January and December, the very months which are characterised by pronounced seasonal effects. In that case, the difference between both decompositions is even more striking. Taking into account upward and downward price changes separately causes a fall in the share of time-dependent pricing from $86 \%$ for the Klenow and Kryvtsov (2006) decomposition to $16 \%$ in the case of our alternative decomposition.

\footnotetext{
${ }^{12}$ For the decomposition in Appendix D the share of the variance terms only, which is equal to the sum of the first six terms of the decomposition, corresponds to $55 \%$ and $80 \%$ including and excluding December and January, respectively. For the Klenow and Kryvtsov (2006) decomposition the share of the variance terms corresponds to $43 \%$ and $92 \%$ including and excluding December and January, respectively. The covariance terms account for the rest of the inflation variance.
} 
All in all, this implies that once the difference between upward and downward adjustments is taken into account, we find that changes in the frequencies of price adjustment play an important role in explaining the evolution of the aggregate inflation rate over time. Contrary to the results in Section 4.1, where this distinction was not made, this is compatible with an important role for state-dependent pricing. These findings are confirmed by the analysis of Hoffmann and Kurz-Kim (2006) for German micro consumer prices.

\subsection{Downward Nominal Rigidity}

The average frequency of a price decrease amounts to $11 \%$, whereas a price increase is only slightly more frequent with $13 \%$. In addition, the average downward price change is as large as the average upward price change, so that we can infer that there is little evidence for downward nominal rigidity. The absence of downward nominal rigidity implies that the distribution of price changes should be symmetric. In order to test the symmetry of the overall distribution of price changes, we calculate the skewness ${ }^{13}$. We find that the skewness is equal to -0.73 , which is very close to zero and negative, whereas downward nominal rigidity would lead to positive skewness. The overall distribution is thus nearly symmetric and does not contain any strong signs of downward nominal rigidity. Finally, it is also worth noting that the distribution of price changes is characterised by a large spike at zero, reflecting the considerable degree of price stickiness which was already brought up in Section 3.
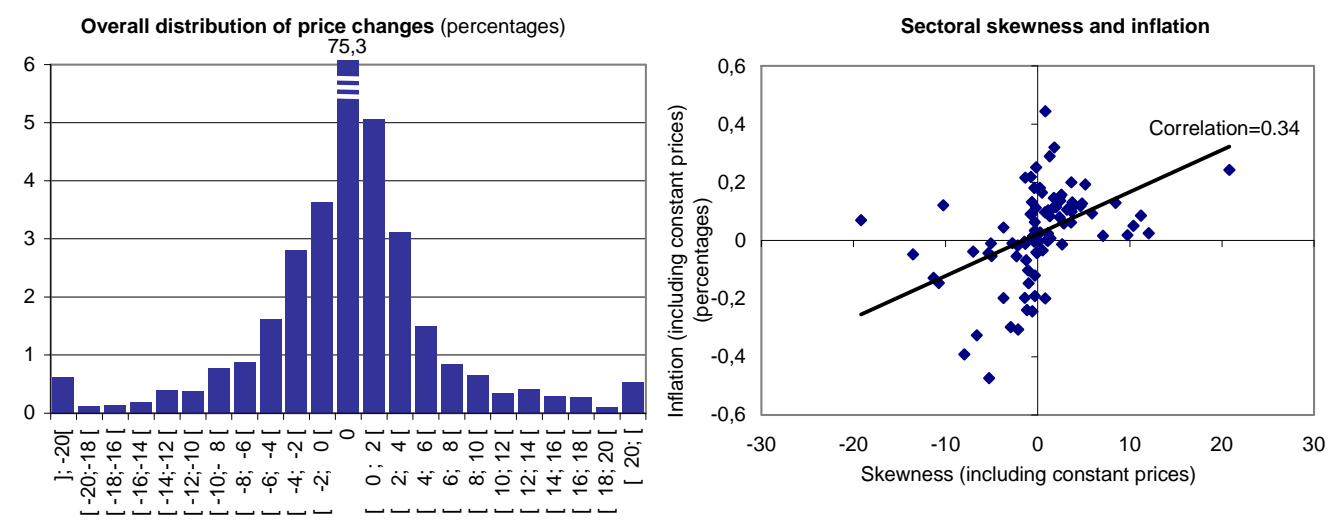

Figure 9: Skewness and Inflation

Even if the industrial sector as a whole does not seem to suffer from downward nominal rigidity, it might still happen that some sectors find it difficult to lower prices. It is often found that wages are downwardly rigid (e.g. Nickell and Quintini, 2003), which might be passed on to prices in sectors with a higher share of wage costs. In case of downward nominal

\footnotetext{
${ }^{13}$ We calculated the weighted skewness using the PPI weights for each price change. The overall distribution of price changes is constructed using the same PPI weights.
} 
rigidity, this would imply positive skewness of the distribution of price changes. However, these sectors would also tend to have higher sectoral inflation and, as e.g. Ball and Mankiw (1994) have pointed out, positive (negative) trend inflation can endogenously generate a positively (negatively) skewed distribution. Therefore, skewness in the distribution of price changes does not necessarily indicate that prices are inherently downwardly (upwardly) rigid. In order to account for this, we calculate the average inflation in each NACE 3-digit sector and link the latter to the skewness of the distribution of price changes of each sector over the entire sample period. We find that various sectors display positive (negative) skewness. However, in Figure 9 we link this skewness to average sectoral inflation and find that, as Ball and Mankiw (1994) predicted, there is a positive correlation of 0.34 between sectoral skewness and trend inflation. This result allows us to conclude that if certain sectors might at first sight seem to suffer from downward nominal rigidity, this is endogenously generated by the sectoral trend inflation.

\subsection{Explaining the Sectoral Heterogeneity}

In this section we assess the heterogeneity in price-setting across different sectors. The purpose is twofold. First, heterogeneity per se is informative about how macroeconomic models should be built. Second, we exploit this heterogeneity in order to gain a better insight into the underlying mechanism of price adjustment. As mentioned before, the analysis of heterogeneity in price adjustment frequencies alone cannot explain whether the sectoral differences are caused by, on the one hand, differences in the cost and/or market structures or, on the other hand, by exogenous differences in price adjustment costs.

Following Álvarez et al. (2005) we exploit the sectoral heterogeneity to find out which factors create this heterogeneity. We regress the sectoral frequencies of price adjustment at the NACE 3-digit level on a number of determinants that are suggested by economic theory. We make a distinction between (i) the overall frequency of a price change, (ii) the frequency of a downward price change, (iii) the frequency of an upward price change and (iv) the difference between the upward and downward frequency. The proxies for the determinants are either calculated on the basis of the Belgian input-output tables ${ }^{14}$ or of the ad hoc survey on price setting for Belgium conducted by Aucremanne and Druant (2005). The specific sources and detailed information are provided in Appendix B. For some sectors, data on the proxies were missing so that they could not be used in the regression. Which sectors are used and which sectors are not, can be found in Table 7 in Appendix C. The same Appendix contains a table with summary statistics of the data we used. In order to assess the robustness of the results, we perform two regressions using a different set of proxies.

\footnotetext{
${ }^{14}$ See Cornille and Robert (2005) for a detailed analysis of the most recent Belgian input-output tables.
} 
The determinants of price adjustment frequency we use, are structured around three blocks. First, we test the importance of some indicators of the cost structure in explaining the cross-sectional differences. Sectors that have more volatile costs should also show relatively higher frequencies of price adjustment. Second, we test the importance of the market structure in explaining the cross-sectional differences. Sectors with lower competition, and thus higher markups, should for equal price adjustment costs be expected to exhibit lower adjustment frequencies, as the firms in these sectors face lower demand elasticities implying that the extent to which they deviate from their profit maximising price has less impact on their total profits. Finally, we also test for the significance of some remaining indicators, most importantly the average size of price adjustments in different sectors. Controlling for variation in the frequency of price adjustment due to differences in the market structure as well as the cost structure, the correlation between price adjustment sizes and frequencies should tell us whether sectoral differences in price adjustment costs are important in explaining differences in price adjustment frequencies. If sectoral differences in price adjustment costs are important, then it can be expected that the size of a price change is significantly negatively correlated with the frequency of price adjustment. In the case of larger (lower) sectoral price adjustment costs, prices should, ceteris paribus, remain unchanged for a longer (shorter) period, creating larger (smaller) percentage price changes.

As we are not sure whether the size of a price change is not contemporaneously determined by the frequency of price adjustment, we cannot exclude that there is an endogeneity problem in our regression. Ordinary Least Squares (OLS) estimation will in that case give biased and inconsistent estimates. In order to get good instruments for the (average) size of price adjustments we do not work with the frequencies and sizes of price adjustment calculated over the sample covering February 2001 to January 2005, but we split the sample in two parts. The first part covers the period from February 2001 to January 2003, while the second part covers the period from February 2003 to January 2005. This enables us to use the (average) sizes calculated over the period February 2001 to January 2003 as instruments for the (average) sizes in an Instrumental Variable (IV) estimation ${ }^{15}$ using the data calculated for the period February 2003 to January 2005. The Hausman test allows us to conclude that the size of price adjustment is in each regression an endogenous regressor, so that the IV estimates are superior to the OLS estimates.

\footnotetext{
${ }^{15} \mathrm{We}$ have tested the quality of the instruments by estimating the reduced form for SIZE/SIZE_UP/SIZE_DOWN. The coefficient of the instrument was each time at least significant at the $5 \%$ significance level.
} 
Table 4: Determinants of Price Adjustment I (74 obs., IV estimation, 2003/2-2005/1)

\begin{tabular}{l|llll}
\hline \hline & FREQ & FREQ_UP & FREQ_DW & FREQ_UP-DW \\
\hline LABOUR & $-1.83^{*}(0.38)$ & $-0.90^{*}(0.22)$ & $-0.94^{*}(0.18)$ & $0.04(0.12)$ \\
ENERGY & $2.05^{*}(0.65)$ & $1.20^{*}(0.38)$ & $0.62^{* * *}(0.36)$ & $0.65^{*}(0.20)$ \\
NON-ENERGY & $0.70^{*}(0.12)$ & $0.29^{*}(0.08)$ & $0.38^{*}(0.06)$ & $-0.02(0.04)$ \\
OUTS_SERV & $1.22^{*}(0.39)$ & $0.58^{* *}(0.24)$ & $0.54^{*}(0.19)$ & $0.07(0.12)$ \\
MKUPMON & $-0.13^{* * *}(0.07)$ & $-0.05(0.04)$ & $-0.08^{* *}(0.03)$ & $0.03(0.02)$ \\
SIZE & $1.25(1.21)$ & - & - & $-0.43(0.38)$ \\
SIZE_UP & - & $1.56(0.95)$ & - & - \\
SIZE_DOWN & - & - & $-0.89(0.84)$ & - \\
SELFSET & $-0.08(0.08)$ & $-0.05(0.05)$ & $-0.05(0.04)$ & $0.00(0.02)$
\end{tabular}

Note: Standard errors of the coefficient estimates are placed between brackets. $* / * * / * * *$ denote coefficient significant at the $1 \% / 5 \% / 10 \%$ significance level The instruments for SIZE, SIZE_UP and SIZE_DOWN are the same variables calculated for the period $2001 / 2-2003 / 1$.

Table 5: Determinants of Price Adjustment II (74 obs., IV estimation, 2003/2-2005/1)

\begin{tabular}{l|llll}
\hline \hline & FREQ & FREQ_UP & FREQ_DW & FREQ_UP-DW \\
\hline LABOUR & $-1.71^{*}(0.37)$ & $-0.84^{*}(0.21)$ & $-0.87^{*}(0.18)$ & $0.03(0.12)$ \\
ENERGY & $2.36^{*}(0.61)$ & $1.23^{*}(0.36)$ & $0.86^{* *}(0.34)$ & $0.58^{*}(0.19)$ \\
NON-ENERGY & $0.67^{*}(0.12)$ & $0.31^{*}(0.08)$ & $0.35^{*}(0.05)$ & $-0.01(0.04)$ \\
OUTS_SERV & $1.01^{* *}(0.40)$ & $0.48^{* *}(0.23)$ & $0.45^{* *}(0.18)$ & $0.07(0.13)$ \\
CCE & $0.18^{* *}(0.07)$ & - & - & $-0.01(0.02)$ \\
CCE_UP & - & $0.10^{* *}(0.04)$ & - & - \\
CCE_DOWN & - & - & $0.09^{* *}(0.03)$ & - \\
SIZE & $0.85(1.16)$ & - & - & $-0.38(0.37)$ \\
SIZE_UP & - & $1.28(0.97)$ & - & - \\
SIZE_DOWN & - & - & $-0.61(0.85)$ & - \\
SELFSET & $-0.20^{* *}(0.09)$ & $-0.11^{* *}(0.05)$ & $-0.10^{* *}(0.04)$ & $0.02(0.02)$ \\
\hline
\end{tabular}

Note: Standard errors of the coefficient estimates are placed between brackets. $* / * * / * * *$ denote coefficient significant at the $1 \% / 5 \% / 10 \%$ significance level

The instruments for SIZE, SIZE UP and SIZE DOWN are the same variables calculated for the period 2001/2-2003/1.

\section{Cost Structure}

Regressing proxies for the shares of labour (LABOUR), energy inputs (ENERGY), nonenergy intermediate inputs (NON-ENERGY) and the degree of outsourcing (OUTS_SERV) in total costs on the frequency of price adjustment (FREQ), we find that the cost structure is a major determinant of the frequency of price adjustment. The share of labour costs significantly decreases the frequency of price adjustment, while the share of energy inputs significantly increases the frequency of price adjustment. This is an intuitive result as the price of energy (labour) inputs changes at the same time frequently (infrequently) and with a large (small) amount. In the same vein, the higher is the share of non-energy intermediate goods and outsourcing, the higher is the frequency of price change. The same conclusions hold for upward and downward price change frequencies separately.

As regards the asymmetry between the frequency of upward and downward price changes, 
we do not find any evidence that a higher share of wages in costs increases the asymmetry. We find an important role for the share of energy prices in explaining sectoral asymmetry in the frequencies. This is not so surprising since energy prices mainly increased over the sample period. Overall, this confirms our earlier conclusions on downward nominal rigidity.

\section{Market Structure}

We also find that the market structure is a determinant of the price change frequency. The first proxy (MKUPMON) for the market power of firms is the share of firms in a particular sector that state that setting the price fully according to their costs and to a self-determined profit margin is an important or very important method to set the price of their main product. We find that higher market power decreases the frequency of price adjustment, as is suggested by theory. In addition, we find that for the frequency of price increases the proxy for market power is less significant, whereas for the frequency of price decreases the proxy plays a more significant role. When a firm with a certain degree of market power experiences a decrease in costs, it decreases its price less often than when costs increase ceteris paribus.

The second proxy (CCE) for the market power of firms reflects the importance attached by firms to competitors' price changes in explaining their own price changes. Firms that need to pay more attention to other firms' prices are likely to work in a more competitive environment than other firms. We find that the higher is the importance of the prices of competitors, the higher is the frequency of price adjustment. So again, lower competition or higher market power decreases the frequency of price adjustment. This result remains valid regardless of the direction of the price change.

\section{Price Adjustment Costs}

Other determinants do not seem to play a significant role. First, we do not find a clear role for the proxy SELFSET, measuring the extent to which a firm's price is set by itself rather than by others (e.g. because the price is regulated by a public authority or because it is set by the parent company). Second, there is no relation between the size and frequency of price adjustment either. Controlling for variation in the frequency of price adjustment due to differences in the cost structure as well as market structure, the insignificant correlation between the sizes of price adjustment (SIZE, SIZE_UP, SIZE_DOWN) and frequencies tells us that sectoral differences in price adjustment costs are unimportant in explaining the cross-sectional difference in price frequencies. 


\section{Pricing-to-Market: Differences between the Behav- iour on the Domestic and Foreign Market}

An important issue in international macroeconomics is pricing-to-market (PTM). Pricingto-market implies that a producer price-discriminates across the geographic destination of the good he sells. Depending on the geographic destination, he will set a different price in his own currency. The opposite is called producer currency pricing (PCP), in which case the price set in the currency of the producer is the same for all geographic destinations. The price abroad is then simply obtained using the prevailing exchange rate. Both practices have different implications for the international transmission of fluctuations.

In this section we compare price setting in the domestic market and in the external market based on the data used for the computation of the PPI. We analyse both the statistics computed using the weights of the respective PPI indices, and unweighted statistics. In the case of unweighted statistics the calculations are based on a sub-sample of prices. For this sub-sample we only selected the prices that are in the same month charged in the Belgian and the external market for the same product, produced by the same firm. We have about 600 such products for which we observe both prices valid in Belgium and prices valid abroad. This results in a sample of about 20,000 valid price quotes. Because of the nature of the data we are only able to assess price-discrimination between the Belgian and foreign market, without knowing which particular country is the destination of the good. For instance, we do not know whether the product reported in the data set is exported to a country within the euro area or outside the euro area. In addition, there is no information on whether or not the price that is valid abroad differs across countries of destination.

Based on the unweighted sub-sample, we find that $38 \%$ of products are sold at a different price abroad than in Belgium. This is somewhat lower than the $60 \%$ of firms in the industrial sector declaring to apply PTM in the survey of Aucremanne and Druant (2005). However, one must keep in mind that their results are turnover-weighted, which might explain the difference. Half of the goods sold at a different price abroad than on the Belgian market are on average $8.7 \%$ more expensive abroad than in Belgium, whereas the other half of goods sold at a different price are on average $16.6 \%$ cheaper abroad than in Belgium. Unfortunately, we can only observe prices ex factory in euro including certain duties and taxes except VAT. This implies that, to the extent that products sold abroad and on the Belgian market are differently taxed, we cannot discriminate between price differences due to differences in market power abroad and in Belgium or due to differences in taxes other than VAT. It can however be assumed that taxes on the external market are on average either lower or higher than taxes on the domestic market. Under the first assumption this will bias the 
share of goods that is sold abroad at a lower price upwardly, while creating a downward bias in the share of goods that are sold abroad at a higher price. Under the second assumption, this will bias upwardly the share of goods sold abroad at a higher price, while creating a downward bias in the share of goods sold abroad at a lower price. Overall, the biases under both assumptions should cancel out, so that we can still consider approximately $38 \%$ of products in the industrial sector to be affected by pricing-to-market.

Table 6: Average Statistics for Domestic and External Market (percentages)

\begin{tabular}{|c|c|c|c|c|c|}
\hline & Change $\left(f r^{+/-}\right)$ & \multicolumn{2}{|c|}{ Up. change $\left(f r^{+}\right)$} & \multicolumn{2}{|c|}{ Down. change $\left(f r^{-}\right)$} \\
\hline & Weight. Unweight. & Weight. & Unweight. & Weight. & Unweight. \\
\hline Dom. market & 20 & 12 & 10 & 9 & 10 \\
\hline \multirow{3}{*}{ Ext. market } & $26 \quad 20$ & & 10 & 13 & 10 \\
\hline & Abs. Change $\left(\left|d p^{+/-}\right|\right)$ & Up. cha & ge $\left(d p^{+}\right)$ & Down. & ange $\left(\left|d p^{-}\right|\right)$ \\
\hline & Weight. $\quad$ Unweight. & Weight. & Unweight. & Weight. & Unweight. \\
\hline Dom. market & 6 & 6 & 5 & 5 & 5 \\
\hline Ext. market & 5 & 6 & 5 & 6 & 5 \\
\hline
\end{tabular}

As far as the patterns of price adjustment across both markets are concerned, we find that based on the weighted statistics prices change more often for goods that are sold abroad than for goods sold in Belgium. However, this seems to be the result of the composition of the basket of goods that is exported. Once we compare the unweighted pairs of prices in our sub-sample, we find that the frequency of price adjustment amounts to $20 \%$ in both markets. The upward, downward and absolute average sizes of a price change in the unweighted sample all amount to $5 \%$, and hardly differ from the average sizes of price adjustment in the weighted sample. Finally, price adjustment is almost perfectly synchronised. When a firm adjusts its prices, it does so at the same time for its domestic and its external prices. This phenomenon gives rise to a very similar pattern for the frequency of price adjustment in both the Belgian and the external market.

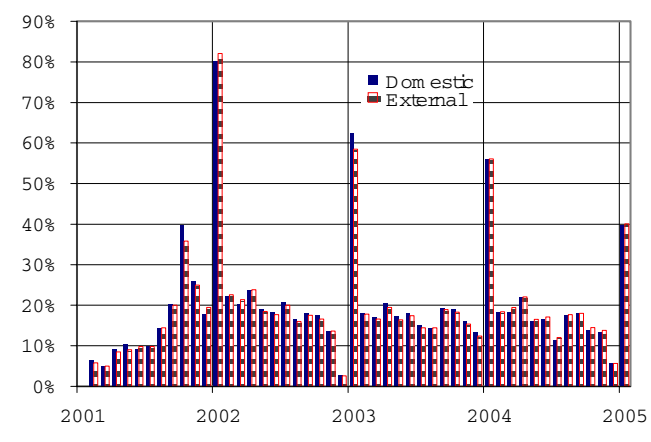

Figure 10: Frequency of Price Adjustment in Foreign and Domestic Market 


\section{A Comparison between Consumer and Producer Price- Setting ${ }^{16}$}

In this section, we compare the characteristics of producer price and consumer price setting. To this end, we exploit the micro PPI data used throughout this paper together with the micro CPI data analysed in Aucremanne and Dhyne (2004). The CPI database covers monthly reports of individual prices used by the NSI for the computation of the Belgian National and Harmonised Index of Consumer Prices, covering the period from January 1996 to February $2003 .{ }^{17}$ For the sample as a whole, more than 120,000 records per month are observed in the raw database. The main differences between both data sets are listed below.

- The CPI data set includes the prices of domestically produced goods as well as the prices of imported goods, whereas the PPI data set covers only domestically produced goods which are sold abroad or on the domestic market.

- The CPI prices include all consumer taxes (excise duty, VAT) whereas PPI prices exclude VAT.

- The sample period for the CPI data set goes from January 1996 to February 2003, whereas the PPI sample goes from January 2001 to January 2005. In order to use as many observations as possible, we exploit the full sample available for both data sets. However, the conclusions we present below have also been obtained on the basis of a common sample for the period from January 2001 to February 2003.

- The sectoral coverage of both data sets is very different. For instance, CPI data include service prices which are not covered in the PPI data set and conversely, the PPI data set includes prices for capital goods or intermediate goods which are excluded from the CPI data set.

- The weighting schemes of both data sets are also very different.

In order to enable a comparison, we restrict the sample to the products covered in both data sets, and conduct the analysis on the basis of unweighted observations. To do so, we make a selection of similar products at the highest level of detail available. For the CPI data this is done at the product level or the 5 digit $\mathrm{COICOP}^{18}$ code and for the PPI data this is done at the level of the 8 digit PRODCOM codes. For the majority of products we find a relatively close correspondence between the two types of products, but in other cases some

\footnotetext{
${ }^{16}$ We thank Emmanuel Dhyne for calculating the statistics for the Belgian CPI micro data.

${ }^{17}$ The CPI data sample used here has been updated up to February 2003 compared to the sample January 1989-January 2001 used in Aucremanne and Dhyne (2004).

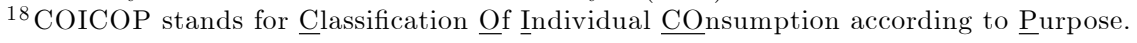


aggregation of products is required. Three situations occurred: (i) different PPI products match one CPI product (for a quarter of the selected products), (ii) different CPI products match one PPI product (only in one case), (iii) different CPI products match different PPI products (one tenth of the selected products). All in all, we obtain 88 comparison points of similar products.

For the matched sample, we compute the following basic statistics: the frequency of price changes, the frequency of price increases, the frequency of price decreases, the average absolute price change, the average price increase and the average price decrease.

We observe that the frequency of price change is generally larger for PPI data than for CPI data (see Figure 11). The same holds for the frequency of price increases and price decreases. The average price change, increase or decrease is smaller for PPI data than for CPI data. This relatively higher frequency and lower size imply that price adjustment costs are smaller for producer products than for consumer products.

Other similar comparisons between CPI and PPI data have been conducted in the IPN framework for Portugal (Dias et al., 2004), for Spain (Álvarez et al., 2005) and for Italy (Sabbatini et al., 2006). Our results are in line with the findings of Álvarez et al. (2005) and Sabbatini et al. (2006), but contradict the findings of Dias et al. (2004), where consumer prices are found to be more flexible than producer prices. Using scanner data, Dutta et al. (2002) find that for 12 refrigerated or frozen orange juices consumer prices are more flexible than wholesale prices. In fact this does not contradict our findings, given that for fruit juice we also observe more flexibility in the CPI than in the PPI. All in all, although matching CPI and PPI micro data is not obvious, the finding that producer prices are more flexible than consumer prices holds for the majority of the available studies. 

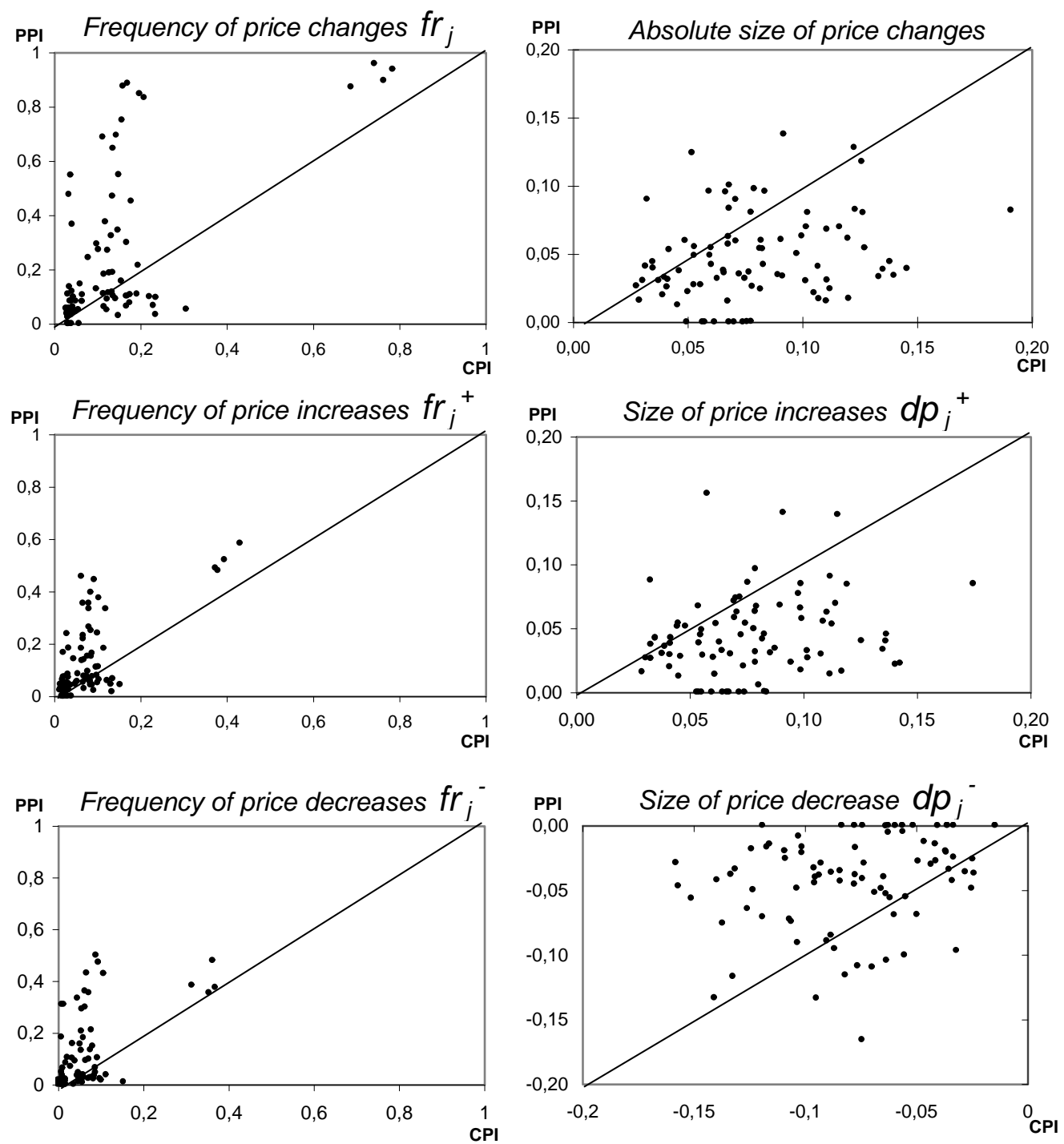

"Sample for CPI data: sample 1996/1-2003/2; for PPI data: sample 2001/1 2005/1.

Figure 11: Comparison of Consumer and Producer Price Setting* (percentages) 


\section{Summary and Conclusions}

In this paper we have analysed the patterns and determinants of price setting in the Belgian industrial sector, using a large micro data set underlying the PPI. The analysis covers a four-year period going from February 2001 to January 2005.

We have found a considerable degree of price stickiness in Belgian producer prices, as on average only one out of four prices changes in a typical month. The median implied duration of a price spell is 7 months, while the average implied duration amounts to 10 months. The overall degree of price stickiness is comparable to the one obtained for the Belgian industrial sector in a survey on price setting (Aucremanne and Druant, 2005). It is also fairly comparable to the degree of price stickiness found in producer prices in Spain, Germany and Portugal. It is however lower than in the case of Belgian consumer prices (Aucremanne and Dhyne, 2004). A similar discrepancy between producer prices and consumer prices was found in Spain and Italy, while in Portugal consumer prices turned out to be less sticky than producer prices.

The average absolute size of a price change is $6 \%$ and is large compared to the prevailing rate of aggregate producer price inflation over the period covered. This suggests that large idiosyncratic shocks play an important role. The observed size is comparable to the results obtained in other European studies of producer prices but smaller than in consumer prices. The combined fact that for producer prices more frequent and smaller changes are observed relative to consumer prices, implies that price adjustment costs are smaller in the case of producer prices.

Across product categories, the frequency of price adjustment is very heterogenous as for some products (energy for instance) it amounts to 50\%, while for others (consumer non-food and capital goods) it is close to $10 \%$. The size of the price changes is far less heterogenous across product categories. This difference in the degree of cross-sectional heterogeneity has two implications. First of all it implies that, in a cross-sectional perspective, the frequencies of price adjustment, rather than the sizes, are the margin along which price setting is made compatible with the sectoral characteristics. Therefore, the heterogeneity in the observed frequencies can be seen as a state-dependent outcome in response to the sector- or productspecific economic conditions. Second, this implies, particularly in the absence of a negative correlation between the frequencies and the sizes, that differences in price adjustment costs do not play an important role in shaping the observed heterogeneity in the degree of price stickiness. By contrast, our econometric analysis shows that differences in firms' cost and market structure are important. In particular, a high share of energy inputs, a low share of labour inputs and a high degree of competition tend to increase the observed frequencies of 
price adjustment.

Price decreases are observed nearly as frequently as price increases, while they are both of the same size in absolute value. Moreover, the overall distribution of price changes which pools all product categories, turns out to be fairly symmetric. Overall, there is not much evidence of structural downward nominal rigidity. We found that, across product categories, the heterogeneity in the skewness of the price change distributions is correlated with the average inflation rate for the product category considered. This result allows us to conclude that if certain sectors at first sight seem to suffer from downward nominal rigidity (i.e. those displaying right skewness in the price change distribution), this is not a structural feature but is endogenously generated by the level of sectoral inflation, as predicted by the model of Ball and Mankiw (1994). Interestingly, we also found negative skewness in the distribution of price changes for those sectors where sectoral inflation is negative.

The frequency of price adjustment displays a clear seasonal pattern. While price adjustment is relatively uncommon in December, it is much more likely in January. This pattern can be compatible with time-dependent characteristics in price setting. However, once the separate role of upward and downward adjustment is taken into account, we also found a considerable degree of variability over time in the frequencies, while the average sizes do not change much over time. This in turn is supportive of state-dependent pricing. This evidence obtained in the time dimension strengthens the evidence mentioned earlier in the cross-sectional dimension. All in all, price setting of producer prices has both timedependent and state-dependent characteristics. Similar conclusions were obtained on the basis of the analysis of consumer prices and in specific surveys on price setting, both in the euro area in general and in Belgium in particular.

Finally, we find that $38 \%$ of products in the industrial sector is affected by pricing-tomarket. This is in line with the findings in the survey of Aucremanne and Druant (2005). 


\section{References}

[1] Altissimo F., Bilke L., Levin A., Mathä T. and B. Mojon, 2006, Sectoral and Aggregate Inflation Dynamics in the Euro Area, Journal of the European Economic Association, forthcoming

[2] Angeloni I., Aucremanne L., Ehrmann M., Galí J., Levin A. and F. Smets, 2006, New Evidence on Inflation Persistence and Price Stickiness in the Euro Area: Implications for Macro Modelling, Journal of the European Economic Association, forthcoming

[3] Álvarez L., Burriel P. and I. Hernando, 2005, Price setting behaviour in Spain: Evidence from micro PPI data, ECB Working Paper, ${ }^{\circ} 522$

[4] Álvarez L., Dhyne E., Hoeberichts M., Kwapil C., Le Bihan H., Lünnemann P., Martins F., Sabbatini R., Stahl H., Vermeulen P. and J. Vilmunen, 2006, Sticky prices in the Euro Area: A Summary of New Micro Evidence, Journal of the European Economic Association, forthcoming

[5] Aucremanne L. and Dhyne E., 2004, How frequently do prices change? Evidence based on the micro data underlying the Belgian CPI, ECB Working Paper, $\mathrm{n}^{\circ} 331$

[6] Aucremanne L. and Druant M., 2005, Price-setting behaviour in Belgium: what can be learned from an ad hoc survey?, ECB Working Paper, $\mathrm{n}^{\circ} 448$

[7] Ball L. and G. Mankiw, 1994, Asymmetric Price Adjustment and Economic Fluctuations, Economic Journal, 104, 247-261

[8] Baudry L., Le Bihan H., Sevestre P. and S. Tarrieu, 2004, Price Rigidity: Evidence from the French CPI Micro-Data, ECB Working Paper, $\mathrm{n}^{\circ} 384$

[9] Benigno P., 2004, Optimal Monetary Policy in a Currency Area, Journal of International Economics, 63, 293-320

[10] Bhaskar V., 2002, On Endogenously Staggered Prices, Review of Economic Studies, $97-116$

[11] Bils M. and P. Klenow, 2004, Some Evidence on the Importance of Sticky Prices, Journal of Political Economy, 112, 947-985

[12] Carlton D., 1986, The Rigidity of Prices, American Economic Review, 76, 637-658

[13] Cecchetti S., 1986, The Frequency of Price Adjustment - A Study of the Newsstand Prices of Magazines, Journal of Econometrics, 31, 255-274 
[14] Chari V., P. Kehoe and E. McGrattan, 2000, Sticky Price Models of the Business Cycle: Can the Contract Multiplier Solve the Persistence Problem?, Econometrica, 68, 1151-1179

[15] Cornille D. and B. Robert, 2005, Sectoral Interdependences and Cost Structure in the Belgian Economy: An Application for Input-Output Tables, National Bank of Belgium Economic Review, 2, 33-48

[16] Dhyne E., Álvarez L., Le Bihan H., Veronese G., Dias D., Hoffmann J., Jonker N., Lunnemann P., Rumler F., and J. Vilmunen, 2006, Price Changes in the Euro Area and the United States: Some Facts from Individual Consumer Price Data, Journal of Economic Perspectives, forthcoming

[17] Dhyne E. and J. Konieczny, 2006, Temporal Distribution of Price Changes: Staggering in the Large and Synchronization in the Small, mimeo

[18] Dias M., Dias D. and P. Neves, 2004, Stylised Features of Price Setting Behaviour in Portugal: 1992-2001, ECB Working Paper, $\mathrm{n}^{\circ} 332$

[19] Dutta S., Bergen M. and D. Levy, 2002, Price Flexibility in Channels of Distribution: Evidence from Scanner Data, Journal of Economic Dynamics and Control, 26, 18451900

[20] Eichenbaum M. and J. Fisher, 2004, Evaluating the Calvo Model of Sticky Prices, mimeo

[21] Eurostat, 2002, Methodology of Short-Term Business Statistics: Interpretation and Guidelines, http://epp.eurostat.cec.eu.int

[22] Golosov M. and R. Lucas, 2005, Menu Costs and Phillips Curves, mimeo

[23] Hoffmann J. and J.-R. Kurz-Kim, 2006, Consumer Price Adjustment Under the Microscope: Germany in a period of Low Inflation, ECB Working Paper, forthcoming

[24] Jeanne O., 1998, Generating Real Persistent Effects of Monetary Shocks: How Much Nominal Rigidity Do We Really Need?, European Economic Review, 42, 1009-1032

[25] Klenow P. and O. Kryvtsov, 2006, State-Dependent or Time-Dependent Pricing: Does it Matter for Recent U.S. Inflation?, Quarterly Journal of Economics, forthcoming

[26] Lach S. and D. Tsiddon, 1992, The Behavior of Prices and Inflation: An Empirical Analysis of Disaggregated Price Data, Journal of Political Economy, 100, 349-389 
[27] Levy D., Müller G., Dutta S. and M. Bergen, 2005, Holiday Price Rigidity and Cost of Price Adjustment, Managerial and Decision Economics, forthcoming

[28] Sabbatini R., Fabiani S., Gatulli A. and G. Veronese, 2006, Producer Price Behaviour in Italy: Evidence from Micro PPI Data, mimeo

[29] Stahl H., 2006, Producer Price Adjustment at the Micro Level: Evidence from Individual Price Records Underlying the German PPI, mimeo

[30] Taylor, J., 1979, Staggered Price Setting in a Macro Model, American Economic Review, $69,108-113$

[31] Taylor, J., 1980, Aggregate Dynamics and Staggered Contracts, Journal of Political Economy, 88, 1-24

[32] Vermeulen P., Dias M., Dossche M., Gautier E., Hernando I., Sabbatini R. and H. Stahl, 2006, Price Setting in the Euro Area: Some Stylised Facts from Individual Producer Price Data and Producer Surveys, mimeo 


\section{Appendix A: Definition of Statistics}

\section{Variables}

We define the following binary variables for a price $p_{i j t}$ of a product in product category $j$ sold by firm $i$ at time $t$ :

- $D E N_{i j t}=\begin{aligned} & 1 \text { if } p_{i j t} \text { and } p_{i j t-1} \text { are observed } \\ & 0 \text { if } p_{i j t} \text { exists but not } p_{i j t-1}\end{aligned}$

- $N U M_{i j t}=\begin{aligned} & 1 \text { if } p_{i j t} \neq p_{i j t-1} \\ & 0 \text { otherwise }\end{aligned}$

- $N U M U P_{i j t}=\begin{aligned} & 1 \text { if } p_{i j t}>p_{i j t-1} \\ & 0 \text { otherwise }\end{aligned}$

- $N U M D O W N_{i j t}=\begin{aligned} & 1 \text { if } p_{i j t}<p_{i j t-1} \\ & 0 \text { otherwise }\end{aligned}$

\section{Time Series Statistics (NACE 4-digit)}

One can calculate the frequency and size of price changes at time $t$ for product category $j$ as:

- Frequency of price changes: $f r_{j t}^{+/-}=\frac{\sum_{i=1}^{n_{j}} N U M_{i j t}}{\sum_{i=1}^{n_{j}} D E N_{i j t}}$

- Frequency of price increases: $f r_{j t}^{+}=\frac{\sum_{i=1}^{n_{j}} N U M U P_{i j t}}{\sum_{i=1}^{n_{j}} D E N_{i j t}}$

- Frequency of price decreases: $f r_{j t}^{-}=\frac{\sum_{i=1}^{n_{j}} N U M D O W N_{i j t}}{\sum_{i=1}^{n_{j}} D E N_{i j t}}$

- Average size of a price change: $d p_{j t}^{+/-}=\frac{\sum_{i=1}^{n_{j}}\left(\ln P_{i j t}-\ln P_{i j t-1}\right)}{\sum_{i=1}^{n_{j}} N U M_{i j t}}$

- Average absolute size of a price change: $\left|d p_{j t}^{+/-}\right|=\frac{\sum_{i=1}^{n_{j}}\left|\ln P_{i j t}-\ln P_{i j t-1}\right|}{\sum_{i=1}^{n_{j}} N U M_{i j t}}$ 
- Average size of a price increase: $d p_{j t}^{+}=\frac{\sum_{i=1}^{n_{j}}\left(\ln P_{i j t}-\ln P_{i j t-1}\right)}{\sum_{i=1}^{n_{j}} N U M U P_{i j t}}$

- Average size of a price decrease: $d p_{j t}^{-}=\frac{\sum_{i=1}^{n_{j}}\left(\left(\ln P_{i j t}-\ln P_{i j t-1}\right)\right)}{\sum_{i=1}^{n_{j}} N U M D O W N_{i j t}}$

where $n_{j}$ is the number of firms selling a product belonging to product category $j$.

\section{Product Level Statistics (NACE 4-digit)}

- Frequency of price changes: $f r_{j}^{+/-}=\frac{\sum_{i=1}^{n_{j}} \sum_{t=2}^{\tau} N U M_{i j t}}{\sum_{i=1}^{n_{j}} \sum_{t=2}^{\tau} D E N_{i j t}}$

- Frequency of price increases: $f r_{j}^{+}=\frac{\sum_{i=1}^{n_{j}} \sum_{t=2}^{\tau} N U M U P_{i j t}}{\sum_{i=1}^{n_{j}} \sum_{t=2}^{\tau} D E N_{i j t}}$

- Frequency of price decreases: $f r_{j}^{-}=\frac{\sum_{i=1}^{n_{j}} \sum_{t=2}^{\tau} N U M D O W N_{i j t}}{\sum_{i=1}^{n_{j}} \sum_{t=2}^{\tau} D E N_{i j t}}$

- Average size of a price change: $d p_{j}^{+/-}=\frac{\sum_{i=1}^{n_{j}} \sum_{t=2}^{\tau}\left(\ln P_{i j t}-\ln P_{i j t-1}\right)}{\sum_{i=1}^{n_{j}} \sum_{t=2}^{\tau} N U M_{i j t}}$

- Average absolute size of a price change: $\left|d p_{j}^{+/-}\right|=\frac{\sum_{i=1}^{n_{j}} \sum_{t=2}^{\tau}\left|\ln P_{i j t}-\ln P_{i j t-1}\right|}{\sum_{i=1}^{n_{j}} \sum_{t=2}^{\tau} N U M_{i j t}}$

- Average size of a price increase: $d p_{j}^{+}=\frac{\sum_{i=1}^{n_{j}} \sum_{t=2}^{\tau}\left(\ln P_{i j t}-\ln P_{i j t-1}\right)}{\sum^{n_{j}} \sum^{\tau}}$

$$
\sum_{i=1}^{n_{j}} \sum_{t=2}^{\tau} N U M U P_{i j t}
$$

- Average size of a price decrease: $d p_{j}^{-}=\frac{\sum_{i=1}^{n_{j}} \sum_{t=2}^{\tau}\left(\left(\ln P_{i j t}-\ln P_{i j t-1}\right)\right)}{\sum_{i=1}^{n_{j}} \sum_{t=2}^{\tau} N U M D O W N_{i j t}}$ 
The product level statistics are subsequently aggregated to statistics at the NACE 3digit, NACE 2-digit or the entire Industry level using the PPI weights. For the total PPI or the entire Industry, this results in the overall frequency of price adjustment $f r^{+/-}$, overall frequency of upward price adjustment $f r^{+}$, overall frequency of downward price adjustment $f r^{-}$, overall price change $d p^{+/-}$, overall absolute price change $\left|d p^{+/-}\right|$, overall downward price change $d p^{-}$and overall upward price change $d p^{+}$.

\section{Appendix B: Definition and sources of the data}

- FREQ: Frequency of price changes. [Source: based on the micro PPI database, at the NACE 3 digit level.]

- FREQ_UP: Frequency of price increases. [Source: see FREQ].

- FREQ_DOWN: Frequency of price decreases. [Source: see FREQ].

- SIZE: average absolute size of price changes. [Source: see FREQ].

- SIZE_UP: average size of upward price changes. [Source: see FREQ].

- SIZE_DOWN: average size of downward price changes. [Source: see FREQ].

- LABOUR: share of labour costs in terms of total costs. [Source: supply and use tables of Belgium for 2000 (sources: NIS and NBB). Based on a classification mixing NACE 2 digit and NACE 3 digit levels. Therefore, if no data were available at the NACE 3 digit level, the corresponding values for the higher NACE 2 digit level have been used]

- ENERGY: share of energy intermediate inputs in terms of total costs. [Source: see LABOUR]

- NON-ENERGY: share of non-energy intermediate goods inputs in terms of total costs. [Source: see LABOUR]

- OUTS_SERV: as a proxy for outsourcing, the share of services intermediate input in terms of total costs. [Source: see LABOUR]

- SELFSET: reflects situations where prices are fixed by the firm itself: they are not fixed by 'others', e.g. the government. [Source: taken from an ad-hoc survey on pricesetting behaviour in Belgium conducted by the NBB - see Aucremanne L. and Druant M. (2004). The indicator has been defined at the NACE 3 digit level. However, some sectors are not covered by the survey. They are mentioned as 'non available' in our database]. 
- CCE: reflects the importance attached by firms to competitors' price changes in explaining their own price changes. Constructed as the share of firms stating that competitors' price changes are 'important' or 'very important' in explaining price changes. [Source: see SELFSET]

- CCE_UP: reflects the importance attached by firms to competitors' price increases in explaining their own price changes. Constructed as the share of firms stating that competitors' price increases are 'important' or 'very important' in explaining price changes [Source: see SELFSET]

- CCE_DOWN: reflects the importance attached by firms to competitors' price decreases in explaining their own price changes. Constructed as the share of firms stating that competitors' price decreases are 'important' or 'very important' in explaining price changes [Source: see SELFSET].

- MKUPMON: the share of firms stating that setting the price fully according to their costs and to a self-determined profit margin is an 'important' or 'very important' method applied to set the price of their main product. In case firms also mentioned that setting their price according to the price of their main competitor(s), meaning that they do not determine their profit margin themselves, is an 'important' or 'very important' method applied to set the price of their main product, the answers are considered to be inconsistent and the observation is dropped. [Source: see SELFSET] 


\section{Appendix C: Additional Tables}

Table 7: Price Adjustment Statistics at the NACE 3-digit level

\begin{tabular}{|c|c|c|c|c|c|c|c|}
\hline \multirow{2}{*}{ Description } & \multirow{2}{*}{$\begin{array}{l}\text { NACE3 } \\
\text { Code }\end{array}$} & \multicolumn{3}{|c|}{ Frequency of price changes } & \multicolumn{3}{|c|}{ Size of price changes } \\
\hline & & Total & Increases & Decreases & Increases & Decreases & Magnitude \\
\hline Mining of non-ferrous metal ores, except uranium and thorium ores & 132 & $10 \%$ & $7 \%$ & $2 \%$ & $21 \%$ & $-29 \%$ & $23 \%$ \\
\hline Quarrying of stone & 141 & $6 \%$ & $5 \%$ & $1 \%$ & $5 \%$ & $-1 \%$ & $4 \%$ \\
\hline Quarrying of sand and clay & 142 & $13 \%$ & $8 \%$ & $5 \%$ & $5 \%$ & $-5 \%$ & $5 \%$ \\
\hline Mining of chemical and fertilizer minerals & 143 & $10 \%$ & $6 \%$ & $4 \%$ & $6 \%$ & $-8 \%$ & $7 \%$ \\
\hline Other mining and quarrying n.e.c. & 145 & $21 \%$ & $17 \%$ & $4 \%$ & $1 \%$ & $-1 \%$ & $1 \%$ \\
\hline Production, processing, preserving of meat, meat products * & 151 & $34 \%$ & $15 \%$ & $18 \%$ & $5 \%$ & $-6 \%$ & $6 \%$ \\
\hline Processing and preserving of fish and fish products * & 152 & $20 \%$ & $11 \%$ & $9 \%$ & $7 \%$ & $-6 \%$ & $6 \%$ \\
\hline Processing and preserving of fruit and vegetables * & 153 & $27 \%$ & $14 \%$ & $13 \%$ & $7 \%$ & $-6 \%$ & $7 \%$ \\
\hline Manufacture of vegetable and animal oils and fats * & 154 & $44 \%$ & $22 \%$ & $22 \%$ & $4 \%$ & $-4 \%$ & $4 \%$ \\
\hline Manufacture of dairy products * & 155 & $25 \%$ & $15 \%$ & $10 \%$ & $3 \%$ & $-3 \%$ & $3 \%$ \\
\hline Manufacture of grain mill products, starches and starch products * & 156 & $29 \%$ & $19 \%$ & $9 \%$ & $2 \%$ & $-2 \%$ & $2 \%$ \\
\hline Manufacture of prepared animal feeds * & 157 & $28 \%$ & $12 \%$ & $15 \%$ & $4 \%$ & $-2 \%$ & $3 \%$ \\
\hline Manufacture of other food products * & 158 & $8 \%$ & $6 \%$ & $2 \%$ & $3 \%$ & $-3 \%$ & $3 \%$ \\
\hline Manufacture of beverages * & 159 & $10 \%$ & $7 \%$ & $3 \%$ & $5 \%$ & $-6 \%$ & $5 \%$ \\
\hline Manufacture of tobacco products & 160 & $12 \%$ & $11 \%$ & $1 \%$ & $3 \%$ & $-3 \%$ & $3 \%$ \\
\hline Preparation and spinning of textile fibres * & 171 & $42 \%$ & $22 \%$ & $20 \%$ & $5 \%$ & $-5 \%$ & $5 \%$ \\
\hline Textile weaving * & 172 & $10 \%$ & $5 \%$ & $5 \%$ & $3 \%$ & $-4 \%$ & $3 \%$ \\
\hline Finishing of textiles* & 173 & $4 \%$ & $3 \%$ & $2 \%$ & $3 \%$ & $-5 \%$ & $3 \%$ \\
\hline Manufacture of made-up textile articles, except apparel * & 174 & $7 \%$ & $4 \%$ & $3 \%$ & $5 \%$ & $-6 \%$ & $6 \%$ \\
\hline Manufacture of other textiles * & 175 & $15 \%$ & $8 \%$ & $7 \%$ & $3 \%$ & $-4 \%$ & $4 \%$ \\
\hline Manufacture of knitted and crocheted fabrics & 176 & $3 \%$ & $2 \%$ & $1 \%$ & $1 \%$ & $0 \%$ & $1 \%$ \\
\hline Manufacture of knitted and crocheted articles * & 177 & $3 \%$ & $2 \%$ & $1 \%$ & $3 \%$ & $-3 \%$ & $4 \%$ \\
\hline Manufacture of leather clothes & 181 & $8 \%$ & $6 \%$ & $2 \%$ & $5 \%$ & $-34 \%$ & $12 \%$ \\
\hline Manufacture of other wearing apparel and accessories * & 182 & $9 \%$ & $4 \%$ & $5 \%$ & $5 \%$ & $-3 \%$ & $4 \%$ \\
\hline Dressing and dyeing of fur; manufacture of articles of fur & 183 & $9 \%$ & $7 \%$ & $2 \%$ & $3 \%$ & $-3 \%$ & $3 \%$ \\
\hline Manufacture of luggage, handbags and the like, saddler * & 192 & $1 \%$ & $1 \%$ & $0 \%$ & $2 \%$ & $0 \%$ & $2 \%$ \\
\hline Manufacture of footwear * & 193 & $6 \%$ & $6 \%$ & $0 \%$ & $3 \%$ & $0 \%$ & $3 \%$ \\
\hline Sawmilling and planing of wood, impregnation of wood * & 201 & $11 \%$ & $5 \%$ & $6 \%$ & $5 \%$ & $-5 \%$ & $5 \%$ \\
\hline Manufacture of veneer sheets; manufacture of plywood, laminboard, particle & & & & & & & \\
\hline board, fibre board and other panels and boards * & 202 & $10 \%$ & $5 \%$ & $5 \%$ & $7 \%$ & $-7 \%$ & $7 \%$ \\
\hline Manufacture of builders' carpentry and joinery * & 203 & $9 \%$ & $6 \%$ & $3 \%$ & $3 \%$ & $-3 \%$ & $3 \%$ \\
\hline Manufacture of wooden containers * & 204 & $9 \%$ & $4 \%$ & $5 \%$ & $3 \%$ & $-3 \%$ & $3 \%$ \\
\hline Manufacture of other products of wood; manufacture of articles of cork, straw & & & $3 \%$ & $2 \%$ & & & $1 \%$ \\
\hline $\begin{array}{l}\text { and plaiting materials * } \\
\text { Manufacture of pulp, paper and paperboard * }\end{array}$ & $\begin{array}{c}205 \\
211\end{array}$ & $\begin{array}{r}5 \% \\
29 \%\end{array}$ & $\begin{array}{r}3 \% \% \\
14 \%\end{array}$ & $15 \%$ & $2 \%$ & $\begin{array}{r}0 \% \\
-4 \%\end{array}$ & $\begin{array}{l}1 \% \\
3 \%\end{array}$ \\
\hline Manufacture of articles of paper and paperboard * & 212 & $25 \%$ & $12 \%$ & $14 \%$ & $4 \%$ & $-4 \%$ & $4 \%$ \\
\hline Publishing & 221 & $8 \%$ & $6 \%$ & $3 \%$ & $0 \%$ & $-1 \%$ & $1 \%$ \\
\hline Printing and service activities related to printing * & 222 & $13 \%$ & $7 \%$ & $6 \%$ & $2 \%$ & $-3 \%$ & $2 \%$ \\
\hline Manufacture of refined petroleum products * & 232 & $89 \%$ & $51 \%$ & $38 \%$ & $5 \%$ & $-7 \%$ & $6 \%$ \\
\hline Manufacture of basic chemicals * & 241 & $44 \%$ & $23 \%$ & $21 \%$ & $7 \%$ & $-8 \%$ & $7 \%$ \\
\hline Manufacture of pesticides and other agro-chemical products & 242 & $4 \%$ & $3 \%$ & $2 \%$ & $5 \%$ & $-7 \%$ & $5 \%$ \\
\hline Manufacture of paints, varnishes and similar coatings, printing ink and mastics * & 243 & $17 \%$ & $9 \%$ & $8 \%$ & $4 \%$ & $-3 \%$ & $4 \%$ \\
\hline Manufacture of pharmaceuticals, medicinal chemicals and botanical products * & 244 & $6 \%$ & $4 \%$ & $2 \%$ & $5 \%$ & $-7 \%$ & $6 \%$ \\
\hline Manufacture of soap, detergents, cleaning, polishing * & 245 & $33 \%$ & $16 \%$ & $17 \%$ & $3 \%$ & $-3 \%$ & $3 \%$ \\
\hline Manufacture of other chemical products * & 246 & $28 \%$ & $14 \%$ & $14 \%$ & $7 \%$ & $-7 \%$ & $7 \%$ \\
\hline Manufacture of man-made fibres & 247 & $30 \%$ & $19 \%$ & $11 \%$ & $4 \%$ & $-5 \%$ & $4 \%$ \\
\hline Manufacture of rubber products * & 251 & $16 \%$ & $8 \%$ & $8 \%$ & $6 \%$ & $-6 \%$ & $6 \%$ \\
\hline Manufacture of plastic products * & 252 & $25 \%$ & $13 \%$ & $12 \%$ & $6 \%$ & $-5 \%$ & $6 \%$ \\
\hline Manufacture of glass and glass products * & 261 & $23 \%$ & $12 \%$ & $11 \%$ & $9 \%$ & $-5 \%$ & $8 \%$ \\
\hline $\begin{array}{l}\text { Manufacture of non-refractory ceramic goods other than for construction } \\
\text { purposes; manufacture of refractory ceramic products }\end{array}$ & 262 & $4 \%$ & $3 \%$ & $2 \%$ & $5 \%$ & $-1 \%$ & $4 \%$ \\
\hline Manufacture of ceramic tiles and flags & 263 & $4 \%$ & $4 \%$ & $1 \%$ & $23 \%$ & $0 \%$ & $18 \%$ \\
\hline Manufacture of bricks, tiles and construction products * & 264 & $21 \%$ & $12 \%$ & $9 \%$ & $3 \%$ & $-2 \%$ & $3 \%$ \\
\hline Manufacture of cement, lime and plaster * & 265 & $5 \%$ & $4 \%$ & $1 \%$ & $3 \%$ & $-3 \%$ & $4 \%$ \\
\hline Manufacture of articles of concrete, plaster, $c$ & 266 & $20 \%$ & $12 \%$ & $8 \%$ & $4 \%$ & $-4 \%$ & $4 \%$ \\
\hline Cutting, shaping and finishing of ornamental and building stone & 267 & $6 \%$ & $4 \%$ & $2 \%$ & $5 \%$ & $-5 \%$ & $5 \%$ \\
\hline Manufacture of other non-metallic mineral products & 268 & $5 \%$ & $3 \%$ & $1 \%$ & $7 \%$ & $-12 \%$ & $8 \%$ \\
\hline Manufacture of basic iron and steel and of ferro-alloys * & 271 & $92 \%$ & $51 \%$ & $41 \%$ & $4 \%$ & $-4 \%$ & $4 \%$ \\
\hline Manufacture of tubes * & 272 & $18 \%$ & $11 \%$ & $7 \%$ & $7 \%$ & $-16 \%$ & $9 \%$ \\
\hline Other first processing of iron and steel * & 273 & $81 \%$ & $51 \%$ & $30 \%$ & $7 \%$ & $-11 \%$ & $8 \%$ \\
\hline Manufacture of basic precious and non-ferrous metals * & 274 & $78 \%$ & $32 \%$ & $45 \%$ & $6 \%$ & $-4 \%$ & $5 \%$ \\
\hline Casting of metals * & 275 & $37 \%$ & $18 \%$ & $19 \%$ & $4 \%$ & $-5 \%$ & $4 \%$ \\
\hline
\end{tabular}

Note: asterisks indicate the sectors used in the regression analysis. 
Table 7 (cont'd): Price Adjustment Statistics at the NACE 3-digit level

\begin{tabular}{|c|c|c|c|c|c|c|c|}
\hline \multirow{2}{*}{ Description } & \multirow{2}{*}{$\begin{array}{l}\text { NACE3 } \\
\text { Code }\end{array}$} & \multicolumn{3}{|c|}{ Frequency of price changes } & \multicolumn{3}{|c|}{ Size of price changes } \\
\hline & & Total & Increases & Decreases & Increases & Decreases & s Magnitude \\
\hline Manufacture of structural metal products * & 281 & $20 \%$ & $11 \%$ & $9 \%$ & $8 \%$ & $-9 \%$ & $8 \%$ \\
\hline $\begin{array}{l}\text { Manufacture of tanks, reservoirs and containers of metal; manufacture of central } \\
\text { heating radiators and boilers * }\end{array}$ & 282 & & $11 \%$ & $8 \%$ & $4 \%$ & $-5 \%$ & $4 \%$ \\
\hline Manufacture of steam generators, except central heating hot water boilers * & 283 & $7 \%$ & $5 \%$ & $2 \%$ & $4 \%$ & $-21 \%$ & $9 \%$ \\
\hline Forging, pressing, stamping and roll forming of metal; powder metallurgy * & 284 & $21 \%$ & $10 \%$ & $11 \%$ & $3 \%$ & $-5 \%$ & $4 \%$ \\
\hline Treatment and coating of metals; general mechanical engineering * & 285 & $8 \%$ & $5 \%$ & $3 \%$ & $4 \%$ & $-8 \%$ & $6 \%$ \\
\hline Manufacture of cutlery, tools and general hardware * & 286 & $0 \%$ & $0 \%$ & $0 \%$ & $0 \%$ & $0 \%$ & $0 \%$ \\
\hline Manufacture of other fabricated metal products * & 287 & $37 \%$ & $21 \%$ & $16 \%$ & $6 \%$ & $-7 \%$ & $6 \%$ \\
\hline Manufacture of machinery for the production and use of mechanical power, & & & & & & & \\
\hline except aircraft, vehicle and cycle engines * & 291 & $5 \%$ & $4 \%$ & $1 \%$ & $4 \%$ & $-8 \%$ & $5 \%$ \\
\hline Manufacture of other general purpose machinery * & 292 & $6 \%$ & $3 \%$ & $3 \%$ & $5 \%$ & $-7 \%$ & $5 \%$ \\
\hline Manufacture of agricultural and forestry machinery * & 293 & $6 \%$ & $4 \%$ & $1 \%$ & $2 \%$ & $-11 \%$ & $4 \%$ \\
\hline Manufacture of machine-tools * & 294 & $9 \%$ & $7 \%$ & $2 \%$ & $3 \%$ & $-4 \%$ & $4 \%$ \\
\hline Manufacture of other special purpose machinery * & 295 & $8 \%$ & $5 \%$ & $3 \%$ & $5 \%$ & $-6 \%$ & $5 \%$ \\
\hline Manufacture of domestic appliances n.e.c. ${ }^{*}$ & 297 & $7 \%$ & $4 \%$ & $3 \%$ & $5 \%$ & $-4 \%$ & $4 \%$ \\
\hline Manufacture of office machinery and computers * & 300 & $50 \%$ & $31 \%$ & $19 \%$ & $3 \%$ & $-8 \%$ & $5 \%$ \\
\hline Manufacture of electric motors, generators and transformers * & 311 & $14 \%$ & $6 \%$ & $8 \%$ & $9 \%$ & $-11 \%$ & $10 \%$ \\
\hline Manufacture of electricity distribution and control apparatus * & 312 & $6 \%$ & $3 \%$ & $2 \%$ & $4 \%$ & $-5 \%$ & $4 \%$ \\
\hline Manufacture of insulated wire and cable * & 313 & $12 \%$ & $5 \%$ & $7 \%$ & $6 \%$ & $-7 \%$ & $7 \%$ \\
\hline Manufacture of accumulators, primary cells and primary batteries & 314 & $4 \%$ & $1 \%$ & $3 \%$ & $1 \%$ & $-15 \%$ & $15 \%$ \\
\hline Manufacture of lighting equipment and electric lamps * & 315 & $6 \%$ & $3 \%$ & $3 \%$ & $8 \%$ & $-12 \%$ & $10 \%$ \\
\hline Manufacture of electrical equipment n.e.c. * & 316 & $9 \%$ & $5 \%$ & $3 \%$ & $10 \%$ & $-9 \%$ & $11 \%$ \\
\hline Manufacture of electronic valves and tubes and other electronic components * & 321 & $10 \%$ & $2 \%$ & $8 \%$ & $2 \%$ & $-3 \%$ & $3 \%$ \\
\hline $\begin{array}{l}\text { Manufacture of television and radio transmitters and apparatus for line } \\
\text { telephony and line telegraphy }\end{array}$ & 322 & $12 \%$ & $3 \%$ & $9 \%$ & $10 \%$ & $-10 \%$ & $10 \%$ \\
\hline Manufacture of television and radio receivers, sound or video recording or & & & & & & & \\
\hline reproducing apparatus and associated goods * & 323 & $38 \%$ & $19 \%$ & $19 \%$ & $2 \%$ & $-2 \%$ & $2 \%$ \\
\hline Manufacture of medical and surgical equipment and orthopaedic appliances * & 331 & $14 \%$ & $8 \%$ & $6 \%$ & $4 \%$ & $-4 \%$ & $4 \%$ \\
\hline Manufacture of instruments and appliances for measuring, checking, $t$ & & & & & & & \\
\hline and other purposes, except industrial process control equip & 332 & $2 \%$ & $1 \%$ & $1 \%$ & $1 \%$ & $-4 \%$ & $3 \%$ \\
\hline Manufacture of industrial process control equipment * & 333 & $3 \%$ & $3 \%$ & $1 \%$ & $0 \%$ & $0 \%$ & $0 \%$ \\
\hline Manufacture of optical instruments,photographic equipement * & 334 & $0 \%$ & $0 \%$ & $0 \%$ & $0 \%$ & $0 \%$ & $0 \%$ \\
\hline Manufacture of motor vehicles * & 341 & $41 \%$ & $24 \%$ & $18 \%$ & $2 \%$ & $-2 \%$ & $2 \%$ \\
\hline Manufacture of bodies (coachwork) for motor vehicles; manufacture of trailers & & & & & & & \\
\hline & 342 & $21 \%$ & $10 \%$ & $11 \%$ & $3 \%$ & $-3 \%$ & $3 \%$ \\
\hline Manufacture of parts, accessories for motor vehicles * & 343 & $2 \%$ & $1 \%$ & $0 \%$ & $2 \%$ & $-1 \%$ & $2 \%$ \\
\hline Manufacture of motorcycles and bicycles * & 354 & $4 \%$ & $4 \%$ & $0 \%$ & $3 \%$ & $0 \%$ & $3 \%$ \\
\hline Manufacture of furniture * & 361 & $6 \%$ & $4 \%$ & $2 \%$ & $4 \%$ & $-4 \%$ & $4 \%$ \\
\hline Manufacture of games and toys & 365 & $10 \%$ & $8 \%$ & $2 \%$ & $2 \%$ & $-2 \%$ & $2 \%$ \\
\hline Miscellaneous manufacturing n.e.c. & 366 & $5 \%$ & $4 \%$ & $1 \%$ & $3 \%$ & $-3 \%$ & $3 \%$ \\
\hline Recycling of non-metal waste and scrap & 372 & $4 \%$ & $3 \%$ & $1 \%$ & $13 \%$ & $-6 \%$ & $11 \%$ \\
\hline Production and distribution of electricity & 401 & $58 \%$ & $39 \%$ & $19 \%$ & $2 \%$ & $-4 \%$ & $3 \%$ \\
\hline Manufacture of gas; distribution of gaseous fuels through mains & 402 & $100 \%$ & $63 \%$ & $38 \%$ & $1 \%$ & $-1 \%$ & $1 \%$ \\
\hline Collection, purification and distribution of water & 410 & $14 \%$ & $10 \%$ & $5 \%$ & $3 \%$ & $-4 \%$ & $3 \%$ \\
\hline
\end{tabular}

Note: asterisks indicate the sectors used in the regression analysis.

Table 8: Summary Statistics of Data Used in Regression Analysis

\begin{tabular}{l|llllll}
\hline \hline & Min. & Max. & Mean & Median & St. Dev. & Sample \\
\hline FREQ & 0.00 & 1.00 & 0.19 & 0.10 & 0.22 & $2003 / 2-2005 / 1$ \\
FREQ_UP & 0.00 & 0.62 & 0.10 & 0.05 & 0.12 & $2003 / 2-2005 / 1$ \\
FREQ_DW & 0.00 & 0.44 & 0.08 & 0.05 & 0.09 & $2003 / 2-2005 / 1$ \\
FREQ_UP-DW & -0.10 & 0.29 & 0.02 & 0.01 & 0.05 & $2003 / 2-2005 / 1$ \\
LABOUR & 0.03 & 0.42 & 0.18 & 0.18 & 0.05 & n.a. \\
ENERGY & 0.00 & 0.18 & 0.03 & 0.02 & 0.04 & n.a. \\
NON-ENERGY & 0.09 & 0.77 & 0.48 & 0.51 & 0.14 & n.a. \\
OUTS_SERV & 0.03 & 0.35 & 0.13 & 0.12 & 0.05 & n.a. \\
MKUPMON & 0.00 & 1.00 & 0.32 & 0.28 & 0.27 & n.a. \\
CCE & 0.00 & 1.00 & 0.52 & 0.56 & 0.27 & n.a. \\
CCE_UP & 0.00 & 1.00 & 0.39 & 0.38 & 0.24 & n.a. \\
CCE_DOWN & 0.00 & 1.00 & 0.48 & 0.51 & 0.27 & n.a. \\
SIZE & 0.00 & 0.30 & 0.05 & 0.04 & 0.04 & $2003 / 2-2005 / 1$ \\
SIZE_UP & 0.00 & 0.35 & 0.05 & 0.05 & 0.04 & $2003 / 2-2005 / 1$ \\
SIZE_DOWN & -0.24 & 0.00 & -0.05 & -0.05 & 0.04 & $2003 / 2-2005 / 1$ \\
SIZE (IV) & 0.00 & 0.17 & 0.04 & 0.03 & 0.03 & $2001 / 2-2003 / 1$ \\
SIZE_UP (IV) & 0.00 & 0.08 & 0.03 & 0.03 & 0.02 & $2001 / 2-2003 / 1$ \\
SIZE_DOWN (IV) & -0.62 & 0.00 & -0.04 & -0.03 & 0.07 & $2001 / 2-2003 / 1$ \\
SELFSET & 0.00 & 1.00 & 0.84 & 0.93 & 0.23 & n.a. \\
\hline
\end{tabular}

Note: for the sources and description of the data we refer to Appendix B. 


\section{Appendix D: Inflation Variance Decomposition}

Analogous to equation (3) we decompose aggregate inflation into:

$$
\pi_{t}=f r_{t}^{+} \cdot d p_{t}^{+}+f r_{t}^{-} \cdot d p_{t}^{-}
$$

where $f r_{t}^{+}$stands for the frequency of upward price adjustment at time $t, d p_{t}^{+}$stands for the average upward price change at time $t, f r_{t}^{-}$stands for the frequency of downward price adjustment at time $t$ and $d p_{t}^{-}$stands for the average downward price change at time $t$. Furthermore,

$$
\begin{aligned}
\pi_{t}= & f r_{t}^{+} d p_{t}^{+}-f r_{t}^{-}\left|d p_{t}^{-}\right| \\
\pi_{t}= & {\left[f r_{t}^{+}-f r_{t}^{-}\right]\left|d p_{t}^{-}\right|+\left[d p_{t}^{+}-\left|d p_{t}^{-}\right|\right] f r_{t}^{+} } \\
\pi_{t}= & \overline{\left[f r_{t}^{+}-f r_{t}^{-}\right]}\left|d p_{t}^{-}\right|+\left[f r_{t}^{+}-f r_{t}^{-}\right] \overline{\left|d p_{t}^{-}\right|} \\
& +\left[\left(f r_{t}^{+}-f r_{t}^{-}\right)-\overline{\left(f r_{t}^{+}-f r_{t}^{-}\right)}\right]\left[\left|d p_{t}^{-}\right|-\overline{\left|d p_{t}^{-}\right|}\right]-\overline{\left[f r_{t}^{+}-f r_{t}^{-}\right]\left|d p_{t}^{-}\right|} \\
& +\overline{\left[d p_{t}^{+}-\left|d p_{t}^{-}\right|\right]} f r_{t}^{+}+\left[d p_{t}^{+}-\left|d p_{t}^{-}\right|\right] \overline{f r_{t}^{+}} \\
& +\left[\left(d p_{t}^{+}-\left|d p_{t}^{-}\right|\right)-\overline{\left(d p_{t}^{+}-\left|d p_{t}^{-}\right|\right)}\right]\left[f r_{t}^{+}-\overline{f r_{t}^{+}}\right]-\overline{\left[d p_{t}^{+}-\left|d p_{t}^{-}\right|\right] f r_{t}^{+}},
\end{aligned}
$$

where $\left|d p_{t}^{-}\right|$stands for the absolute size of downward price changes. Barred variables represent averages calculated over time $t$. The variance of inflation can then be decomposed in the following way ${ }^{19}$ :

$$
\begin{aligned}
\operatorname{Var}\left(\pi_{t}\right)= & \underbrace{\operatorname{Var}\left(\overline{\left[f r_{t}^{+}-f r_{t}^{-}\right]}\left|d p_{t}^{-}\right|\right)}_{\text {TDP }}+\underbrace{\operatorname{Var}\left(\left[f r_{t}^{+}-f r_{t}^{-}\right] \overline{\left|d p_{t}^{-}\right|}\right)}_{S D P} \\
& +\underbrace{\operatorname{Var}\left(\left[\left(f r_{t}^{+}-f r_{t}^{-}\right)-\overline{\left(f r_{t}^{+}-f r_{t}^{-}\right)}\right]\left[\left|d p_{t}^{-}\right|-\overline{\left|d p_{t}^{-}\right|}\right]\right)}_{S D P} \\
& +\underbrace{\operatorname{Var}\left(\overline{\left[d p_{t}^{+}-\left|d p_{t}^{-}\right|\right]} f r_{t}^{+}\right)}_{S D P}+\underbrace{\operatorname{Var}\left(\left[d p_{t}^{+}-\left|d p_{t}^{-}\right|\right] \overline{f r_{t}^{+}}\right)}_{\text {TDP }} \\
& +\underbrace{\operatorname{Var}\left(\left[\left(d p_{t}^{+}-\left|d p_{t}^{-}\right|\right)-\overline{\left.\left.\left(d p_{t}^{+}-\left|d p_{t}^{-}\right|\right)\right]\left[f r_{t}^{+}-\overline{f r_{t}^{+}}\right]\right)}\right.\right.}_{S D P} \\
& +\underbrace{2 \operatorname{Cov}\left(\overline{\left[f r_{t}^{+}-f r_{t}^{-}\right]}\left|d p_{t}^{-}\right|,\left[f r_{t}^{+}-f r_{t}^{-}\right] \overline{\left|d p_{t}^{-}\right|}\right)}_{S D P}
\end{aligned}
$$

more on next page ...

${ }^{19}$ The components that are classified as being driven by time-dependent pricing are indicated with 'TDP', while the components that are driven by state-dependent pricing are indicated with 'SDP'. 


$$
\begin{aligned}
& +\underbrace{2 \operatorname{Cov}\left(\overline{\left[f r_{t}^{+}-f r_{t}^{-}\right]}\left|d p_{t}^{-}\right|, \overline{\left[d p_{t}^{+}-\left|d p_{t}^{-}\right|\right]} f r_{t}^{+}\right)}_{S D P} \\
& +\underbrace{2 \operatorname{Cov}\left(\overline{\left[f r_{t}^{+}-f r_{t}^{-}\right]}\left|d p_{t}^{-}\right|,\left[d p_{t}^{+}-\left|d p_{t}^{-}\right|\right] \overline{f r_{t}^{+}}\right)}_{\text {TDP }} \\
& +\underbrace{2 \operatorname{Cov}\left(\overline{\left[f r_{t}^{+}-f r_{t}^{-}\right]}\left|d p_{t}^{-}\right|,\left[\left(d p_{t}^{+}-\left|d p_{t}^{-}\right|\right)-\overline{\left(d p_{t}^{+}-\left|d p_{t}^{-}\right|\right)}\right]\left[f r_{t}^{+}-\overline{\left.f r_{t}^{+}\right]}\right)\right.}_{S D P} \\
& +\underbrace{2 \operatorname{Cov}\left(\left[f r_{t}^{+}-f r_{t}^{-}\right] \overline{\left|d p_{t}^{-}\right|},\left[\left(f r_{t}^{+}-f r_{t}^{-}\right)-\overline{\left(f r_{t}^{+}-f r_{t}^{-}\right)}\right]\left[\left|d p_{t}^{-}\right|-\overline{\left|d p_{t}^{-}\right|}\right]\right)}_{S D P} \\
& +\underbrace{2 \operatorname{Cov}\left(\left[f r_{t}^{+}-f r_{t}^{-}\right] \overline{\left|d p_{t}^{-}\right|}, \overline{\left[d p_{t}^{+}-\left|d p_{t}^{-}\right|\right]} f r_{t}^{+}\right)}_{S D P} \\
& +\underbrace{2 \operatorname{Cov}\left(\left[f r_{t}^{+}-f r_{t}^{-}\right] \overline{\left|d p_{t}^{-}\right|},\left[d p_{t}^{+}-\left|d p_{t}^{-}\right|\right] \overline{f r_{t}^{+}}\right)}_{S D P} \\
& +\underbrace{2 \operatorname{Cov}\left(\left[f r_{t}^{+}-f r_{t}^{-}\right] \overline{\left|d p_{t}^{-}\right|},\left[\left(d p_{t}^{+}-\left|d p_{t}^{-}\right|\right)-\overline{\left(d p_{t}^{+}-\left|d p_{t}^{-}\right|\right)}\right]\left[f r_{t}^{+}-\overline{f r_{t}^{+}}\right]\right)}_{S D P} \\
& +\underbrace{2 \operatorname{Cov}\left(\left[\left(f r_{t}^{+}-f r_{t}^{-}\right)-\overline{\left(f r_{t}^{+}-f r_{t}^{-}\right)}\right]\left[\left|d p_{t}^{-}\right|-\overline{\left|d p_{t}^{-}\right|}\right], \overline{\left[d p_{t}^{+}-\left|d p_{t}^{-}\right|\right]} f r_{t}^{+}\right)}_{S D P} \\
& +\underbrace{2 \operatorname{Cov}\left(\left[\left(f r_{t}^{+}-f r_{t}^{-}\right)-\overline{\left(f r_{t}^{+}-f r_{t}^{-}\right)}\right]\left[\left|d p_{t}^{-}\right|-\overline{\left|d p_{t}^{-}\right|}\right],\left[d p_{t}^{+}-\left|d p_{t}^{-}\right|\right] \overline{f r_{t}^{+}}\right)}_{S D P} \\
& +\underbrace{2 \operatorname{Cov}\left(\begin{array}{c}
{\left[\left(f r_{t}^{+}-f r_{t}^{-}\right)-\overline{\left(f r_{t}^{+}-f r_{t}^{-}\right)}\right]\left[\left|d p_{t}^{-}\right|-\overline{\left|d p_{t}^{-}\right|}\right]} \\
{\left[\left(d p_{t}^{+}-\left|d p_{t}^{-}\right|\right)-\overline{\left(d p_{t}^{+}-\left|d p_{t}^{-}\right|\right)}\right]\left[f r_{t}^{+}-\overline{f r_{t}^{+}}\right]}
\end{array}\right)}_{S D P} \\
& +\underbrace{2 \operatorname{Cov}\left(\overline{\left[d p_{t}^{+}-\left|d p_{t}^{-}\right|\right]} f r_{t}^{+},\left[d p_{t}^{+}-\left|d p_{t}^{-}\right|\right] \overline{f r_{t}^{+}}\right)}_{S D P} \\
& +\underbrace{2 \operatorname{Cov}\left(\overline{\left[d p_{t}^{+}-\left|d p_{t}^{-}\right|\right]} f r_{t}^{+},\left[\left(d p_{t}^{+}-\left|d p_{t}^{-}\right|\right)-\overline{\left(d p_{t}^{+}-\left|d p_{t}^{-}\right|\right)}\right]\left[f r_{t}^{+}-\overline{f r_{t}^{+}}\right]\right)}_{S D P} \\
& +\underbrace{2 \operatorname{Cov}\left(\left[d p_{t}^{+}-\left|d p_{t}^{-}\right|\right] \overline{f r_{t}^{+}},\left[\left(d p_{t}^{+}-\left|d p_{t}^{-}\right|\right)-\overline{\left(d p_{t}^{+}-\left|d p_{t}^{-}\right|\right)}\right]\left[f r_{t}^{+}-\overline{f r_{t}^{+}}\right]\right)}_{S D P}
\end{aligned}
$$




\section{European Central Bank Working Paper Series}

For a complete list of Working Papers published by the ECB, please visit the ECB's website (http://www.ecb.int)

585 "Are specific skills an obstacle to labor market adjustment? Theory and an application to the EU enlargement” by A. Lamo, J. Messina and E. Wasmer, February 2006.

586 "A method to generate structural impulse-responses for measuring the effects of shocks in structural macro models" by A. Beyer and R. E. A. Farmer, February 2006.

587 “Determinants of business cycle synchronisation across euro area countries” by U. Böwer and C. Guillemineau, February 2006.

588 "Rational inattention, inflation developments and perceptions after the euro cash changeover" by M. Ehrmann, February 2006.

589 "Forecasting economic aggregates by disaggregates" by D. F. Hendry and K. Hubrich, February 2006.

590 "The pecking order of cross-border investment" by C. Daude and M. Fratzscher, February 2006.

591 "Cointegration in panel data with breaks and cross-section dependence" by A. Banerjee and J. L. Carrion-i-Silvestre, February 2006.

592 "Non-linear dynamics in the euro area demand for MI" by A. Calza and A. Zaghini, February 2006.

593 “Robustifying learnability” by R. J. Tetlow and P. von zur Muehlen, February 2006.

594 “The euro's trade effects" by R. Baldwin, comments by J. A. Frankel and J. Melitz, March 2006

595 "Trends and cycles in the euro area: how much heterogeneity and should we worry about it?" by D. Giannone and L. Reichlin, comments by B. E. Sørensen and M. McCarthy, March 2006.

596 "The effects of EMU on structural reforms in labour and product markets" by R. Duval and J. Elmeskov, comments by S. Nickell and J. F. Jimeno, March 2006.

597 "Price setting and inflation persistence: did EMU matter?" by I. Angeloni, L. Aucremanne, M. Ciccarelli, comments by W. T. Dickens and T. Yates, March 2006.

598 "The impact of the euro on financial markets" by L. Cappiello, P. Hördahl, A. Kadareja and S. Manganelli, comments by X. Vives and B. Gerard, March 2006.

599 "What effects is EMU having on the euro area and its Member Countries? An overview" by F. P. Mongelli and J. L. Vega, March 2006.

600 “A speed limit monetary policy rule for the euro area” by L. Stracca, April 2006.

601 "Excess burden and the cost of inefficiency in public services provision" by A. Afonso and V. Gaspar, April 2006. 
602 "Job flow dynamics and firing restrictions: evidence from Europe" by J. Messina and G. Vallanti, April 2006.

603 “Estimating multi-country VAR models" by F. Canova and M. Ciccarelli, April 2006.

604 “A dynamic model of settlement” by T. Koeppl, C. Monnet and T. Temzelides, April 2006.

605 “(Un)Predictability and macroeconomic stability” by A. D’Agostino, D. Giannone and P. Surico, April 2006.

606 "Measuring the importance of the uniform nonsynchronization hypothesis" by D. A. Dias, C. Robalo Marques and J. M. C. Santos Silva, April 2006.

607 "Price setting behaviour in the Netherlands: results of a survey" by M. Hoeberichts and A. Stokman, April 2006.

608 "How does information affect the comovement between interest rates and exchange rates?" by M. Sánchez, April 2006.

609 "The elusive welfare economics of price stability as a monetary policy objective: why New Keynesian central bankers should validate core inflation” by W. H. Buiter, April 2006.

610 "Real-time model uncertainty in the United States: the Fed from 1996-2003" by R. J. Tetlow and B. Ironside, April 2006.

611 "Monetary policy, determinacy, and learnability in the open economy” by J. Bullard and E. Schaling, April 2006.

612 "Optimal fiscal and monetary policy in a medium-scale macroeconomic model" by S. Schmitt-Grohé and M. Uribe, April 2006.

613 "Welfare-based monetary policy rules in an estimated DSGE model of the US economy" by M. Juillard, P. Karam, D. Laxton and P. Pesenti, April 2006.

614 "Expenditure switching vs. real exchange rate stabilization: competing objectives for exchange rate policy” by M. B. Devereux and C. Engel, April 2006.

615 “Quantitative goals for monetary policy” by A. Fatás, I. Mihov and A. K. Rose, April 2006.

616 "Global financial transmission of monetary policy shocks" by M. Ehrmann and M. Fratzscher, April 2006.

617 "New survey evidence on the pricing behaviour of Luxembourg firms" by P. Lünnemann and T. Y. Mathä, May 2006.

618 "The patterns and determinants of price setting in the Belgian industry" by D. Cornille and M. Dossche, May 2006. 
